\title{
Temporal Evolution of the Resistance Genotypes of Plasmodium Falciparum in Isolates From Equatorial Guinea During 20 Years (1999 to 2019).
}

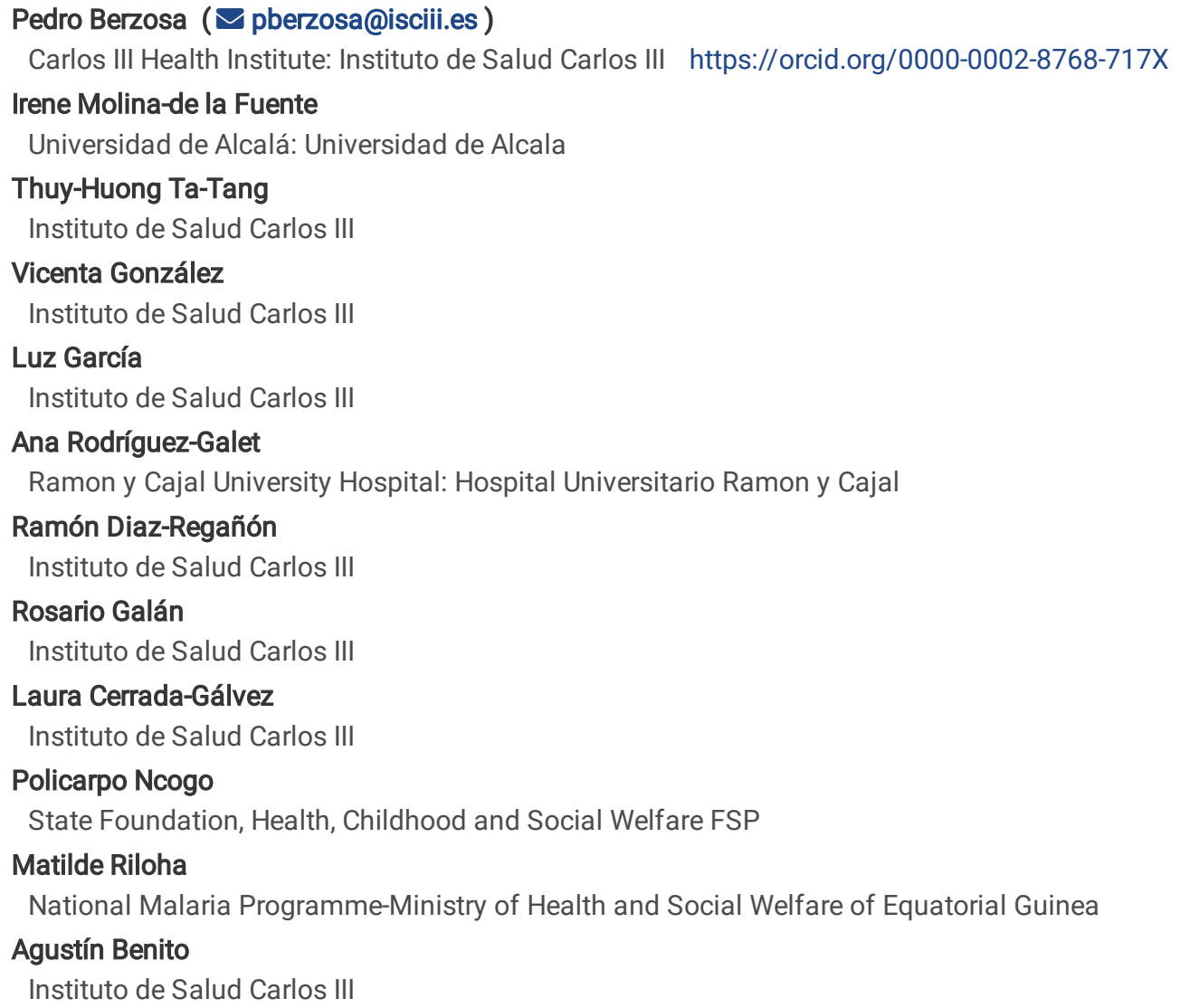

\section{Research Article}

Keywords: malaria, resistance, genes, ACTs, Equatorial Guinea

Posted Date: September 20th, 2021

DOl: https://doi.org/10.21203/rs.3.rs-903234/v1

License: (c) (i) This work is licensed under a Creative Commons Attribution 4.0 International License. Read Full License 


\section{Abstract}

Background: Malaria is one of the deadliest disease in the world, particularly in Africa. The resistance to antimalarial drugs is one of the most important problems to global malaria control. The study assess the evolution of the different resistance markers over time and the possible influence of the interventions and treatment changes that have been made in Equatorial Guinea.

Methods: 1223 biological samples distributed from 1999 to 2019 were included in the study. The screening of the mutations in pfdhfr, pfdhps, pfmdr1 and pfcrt genes were carried out by nested PCR and RFLPs, and the study of pfk13 genes was carried out by nested PCR, followed by sequencing to determine the presence of mutations

Results: the haplotypes partially and fully resistant ( $p f d h f r+p f d h p s)$ increase over time. In 2019, the fully resistant is increasing although super resistant remains lower. There is also a continued decline over time in pfmdr1 and pfcrt gene mutations. Since 2008, when ACTs were introduced in the country, the number of mutations detected in $p f k 13$ has been increasing over time, with more mutations being observed in 2019. In this year, were detected 2 synonymous and 5 non-synonymous mutations, although are not related to resistance to ACTs. In addition, the non-synonymous A578S mutation, the most frequent on the African continent, was detected in 2013 , although it has not been detected in the following years.

Conclusions: The withdrawal of the use of $\mathrm{CQ}$ as a treatment in the country has been effective over time, as wild-type parasite populations outnumber mutant populations. The upward trend observed in SP resistance markers evidence its misuse alone or in combination with AS or AQ in some areas of the country, this allows selective pressure from SP to continue. SNPs $540 \mathrm{E}$ and $581 \mathrm{G}$ do not exceed the limit of $50 \%$ and $10 \%$ respectively, which means that SP as an IPT is still effective in the country. As for the pfk 13 gene, no mutations have been detected in relation to resistance to ACTs. However, in 2019 there is a greater accumulation of non-synonymous mutations compared to years prior to 2008.

\section{Introduction}

Although malaria control has increased significantly worldwide, this parasitic disease remains one of the deadliest in the world, particularly in Africa, where $85 \%$ of fatal cases occur. Indeed, an estimated 229 million cases of malaria and 409,000 deaths were recorded in 2019 [1]. In Equatorial Guinea, a country located in West Central Africa, Plasmodium infections are one of the leading causes of disease, with an incidence rate of 352,124 cases per year, and they are responsible for $15 \%$ of deaths among children under the age of 5 years.

The main strategy for malaria control is quick and accurate diagnosis followed by effective treatment [2]. To ensure the efficacy of the treatment, therapeutic efficacy studies of first- and second-line antimalarial treatments should be carried out at least once every two years, as recommended in the WHO standard protocol for monitoring drug efficacy [3]. This provides confirmation that the treatment continues to work properly and the patient is guaranteed to receive quality treatment. In 2009, Equatorial Guinea adopted artemisinin-based combination therapy (ACT), specifically artesunate-amodiaquine (ASAQ), as first-line treatment $[4,5]$. However, after the latest therapeutic efficacy study carried out in that country [6], the first-line treatment for uncomplicated malaria was changed from ASAQ to artemether/lumefantrine (AL) [7].

The emergence of drug resistance, particularly among $P$. falciparum parasites, the most prevalent species in the country, has been a major contributor to the global burden of malaria in the past 30 years [8]. Indeed, resistance is the most likely explanation for the doubling of malariarelated child deaths in eastern and southern Africa [9].

Similarly, the spread of antimalarial resistance in $P$. falciparum parasites has also been a major obstacle to global malaria control and eradication [10]. The emergence of resistance to chloroquine (CQ) led to its substitution by sulfadoxine/pyrimethamine (SP), which was widely introduced for the treatment of uncomplicated $P$. falciparum malaria [11], although an increase in parasite resistance to SP subsequently occurred. Nowadays, although is not useful as a treatment in Africa due to widespread drug resistance, it is routinely implemented as an intermittent preventive treatment (IPT) for malaria, particularly during pregnancy (IPTp) and in infants (IPTi) [12, 13]. Given the importance of the use of IPT for disease prevention in the most vulnerable groups, it would be of particular use to determine the temporal evolution of resistance to SP [14]. In this context, surveillance of molecular resistance markers plays a key role in the decision-making process for malaria control.

Resistance to SP has been associated with a single nucleotide polymorphism (SNP) in two different genes, namely the dihydrofolate reductase (pfdhfr) and dihydropteroate synthase (pfdhps) genes, which encode for the enzymes PfDHFR and PfDHPS, respectively, both of which are important in the folate synthesis pathway $[15,16]$. N51I, C59R, S108N, and I164L mutations in the pfdhfr gene confer pyrimethamine resistance, and A437G, K540E and A581G mutations in the pfdhps gene confer sulfadoxine resistance [17]. Naidoo et al. have described three combinations of Single Nucleotide Polymorphism (SNPs) related to SP resistance: partially resistant (quadruple mutant: $p f d h f r 51 / 59 R / 108 \mathrm{~N}+$ pfdhps 437G), haplotype IRNG; fully resistant (quintuple mutant: pfdhfr 51I/59R/108N + pfdhps 437G/540E), haplotype IRNGE; and super resistant (sextuple mutant: pfdhfr 51I/59R/108N + pfdhps 437G/540E/581G), haplotype IRNGEG [18]. 
The K76T mutation in the chloroquine-resistant transporter gene ( $p f c r t)$ has been associated with AQ and CQ resistance. Indeed, different studies carried out in Sub-Saharan African countries, such as South Eastern Cameroon [19], Kenya and Malawi, have suggested that the withdrawal of CQ pressure from the population led to a gradual reduction in the proportion of circulating mutant genotypes of the $P f c r t$ gene, thereby increasing the wild genotypes in the population [20-23]. Moreover, SNPs at positions N86Y and D1246Y in pfmdr1 ( $P$. falciparum multidrug resistance gene) were associated with modulated parasite tolerance and susceptibility to a number of anti-malarial drugs, including quinine, AQ, CQ (although it plays a secondary role here), mefloquine (MQ), and lumefantrine (L) [24]. Furthermore, amplifications of the pfmdr1 gene may cause resistance to artesunate, and there is some evidence that AQ use may induce selection of the pfcrt T76 and pfmdr1 Y86 mutant alleles [25]. This finding may provide some insight into the cross-resistance observed between CQ and AQ in vivo. Mutant pfcrt T76 and pfmdr1 Y86 alleles, which are currently used as molecular markers for CQ resistance, may also be useful for monitoring the spread of AQ resistance, such as in West Africa [24].

With regard to the resistance of $P$. falciparum to artemisinina (ART) and its derivatives, this has been widely documented in Southeast Asia (SEA) [26]. As such, the recent gains in global malaria control as a result of ACT treatments are threatened by the emergence of artemisinin resistance in SEA and the probable spread to sensitive areas [27]. However, comparatively speaking, only low-level ART resistance has been identified in Africa to date [28]. Despite this, ongoing worldwide surveillance is still necessary due to the potential public-health impact such resistance could have, especially in children under 5 years of age and pregnant women from Africa, as well as nonimmune travellers [28]. ART resistance in the SEA region has been linked to the kelch propeller domain on chromosome $13(p f k 13)[29,30]$, therefore, single nucleotide polymorphisms (SNPs) and consequent amino acid changes in the gene that occurred because of drug pressure are typically used as molecular markers. The pfk13 resistance markers are non-synonymous mutations and include F446I, N458Y, M476I, Y493H, R539T, I543T, P553L, R561H, P574L and C580Y [31, 32] as validated markers. The principal mutations related with resistance are C580Y, Y493H, R539T, I543T, and N458Y, which were observed in all isolates with the slow-clearance phenotypic trait. The principal mutations associated with resistance observed in African isolates are C580Y, seen in Cameroon, and Y493H, seen in Ghana. Other mutations observed in ART-resistant parasites from the SEA region, which have also been described in African isolates, include S522C, P553L, R561H, A675V, and H719N [33]. The other predominant pfk13 non-synonymous mutation found in African isolates is A578S, which has been observed in all African countries in which pfk13 mutations have been typed, although there is no phenotypic association with ART resistance [34]. However, since it is close to the validated mutation C580Y, which is known to be related to resistance, it is thought that A578S may be the mutant for ART resistance in African isolates [35, 36] even though there is no phenotypic association with ART resistance. Of all the pfk13 mutations observed only in African isolates, and not in SEA isolates, none has yet been directly linked to ART resistance; therefore further investigations are still needed [32, 37].

The objectives of this study were to determine the temporal trends in the prevalence of multi-locus antimalarial resistance markers in $P$. falciparum isolates collected from clinical sources in Equatorial Guinea between 1999 and 2019. This includes analysis of the evolution of markers associated with SP resistance ( $p f d h f r$ and $p f d h p s), A Q$ and CQ resistances ( $p f m d r 1$ and $p f c r t)$ and artemisinin resistance ( $p f k 13)$. This study also offers the opportunity to observe the evolution of the different resistance markers over time and the possible influence of the different interventions and treatment changes made in the country.

\section{Materials And Methods}

\section{Biological samples and location}

All samples used in this study come from the biological samples collection of the National Centre of Tropical Medicine, which is registered with the National Biobank at the Institute of Health Carlos III (Madrid, Spain) in accordance with Spanish Law RD 1716/2011, under registration number C0005278. The samples selected were obtained between 1999 and 2019 as part of different studies carried out in Equatorial Guinea in collaboration with the National Malaria Control Programme of the Ministry of Health and Social Welfare. Table 1 shows the different efficacy studies carried out between 1990-92 and 2019, along with the different changes in treatment in that country and the year of the samples analysed in the study.

\section{Treatments and efficacy studies carried out over time in Equatorial Guinea}


$1990-92$

- In vitro susceptibility of $P$. falciparum to CQ, AQ, MQ and SP in Equatorial Guinea [44].

1996*

- Resistance: $55 \%$ CQ

1999*

- Use of CQ as treatment. An efficacy study was conducted and a resistance of $40 \%$ was found and $16 \%$ to SP [45]. CQ was withdrawal.

2001*

- SP as a treatment in the country

$2002 / 2003$

- Study of the efficacy of the combinations AS-SP, 95\% of efficacy (unpublished study)

2004*

- AS-SP in the country

2005*

- Study of the efficacy of the combinations AS-SP and AQ-SP [4].

2006*

- ASSP and AQSP

- Efficacy study of ASAQ [5]

2008

- Change of official treatment, $1^{\text {st }}$ line ASAQ, $2^{\text {nd }}$ line AL

2010

- Efficacy study of ASAQ (unpublished study) 95\% efficacy

2011*

- $1^{\text {st }}$ line ASAQ, $2^{\text {nd }}$ line AL

2013*

- $1^{\text {st }}$ line ASAQ, $2^{\text {nd }}$ line AL

2016*

- $1^{\text {st }}$ line ASAQ, $2^{\text {nd }}$ line AL

2018

$1^{\text {st }}$ line ASAQ, $2^{\text {nd }}$ line AL

- Efficacy study of ASAQ and AL [6]

2019*

- $1^{\text {st }}$ line ASAQ, $2^{\text {nd }}$ line AL

2020

- Change of official treatment, $1^{\text {st }} A L$ y $2^{\text {nd }} A S A Q$

Table 1.- It shows the different efficacy studies that have been carried out over time in Equatorial Guinea from 1990-92 to 2020. How the treatments have changed in each year is indicated. Years marked with asterisk (*) indicate the years from which samples were taken from the collection of the National Centre for Tropical Medicine. The column "samples" indicates the number of samples that have been analysed for each year included in the study. Chloroquine (CQ), Amodiaquine (AQ), Mefloquine (MQ), sulfadoxine/pyrimethamine (SP), artesunate (AS), lumefantrine $(\mathrm{L})$ and artemether $(\mathrm{A})$.

Equatorial Guinea is located in West Central Africa. It is divided into an Insular Region (Bioko Island, where the capital city, Malabo, is located, and Anobón, Elobey and Corisco), with the Continental Region lying between Cameroon and Gabon (Figure 1).

The samples in the collection are dried finger blood on Whatman $903^{\mathrm{TM}}$ (GE Healthcare Bio-Sciences Corp.) from patients with malaria diagnosed by microscopy and confirmed by Nested Multiplex Malaria PCR (NM-PCR). All samples were stored at $-20^{\circ} \mathrm{C}$.

\section{Molecular biology}

Samples diagnosed as falciparum malaria by microscopy, and subsequently confirmed by NM-PCR [38,39], were selected to screen the mutations related to drug resistance in the $P$. falciparum genes pfdhfr, pfdhps, pfmdr1, pfcrt and pfk13. 
1) DNA extraction: DNA was extracted from the above samples using the Saponin/Chelex method [40] with minor modifications for our laboratory. Thus, a 5-mm diameter punch containing $10 \mu \mathrm{L}$ of blood was used. The tube containing the the isolated DNA was then labelled with the sample number, year and place of origin of the sample. These DNA samples were used immediately for PCR or stored at $-20^{\circ} \mathrm{C}$ until used.

2) Nested PCR molecular markers for resistance: The $P$. falciparum genes $p f d h f r, p f d h p s, p f m d r 1, p f c r t$ and $p f k 13$ were analysed. Mutation screening was performed as described in Maryland University Protocols by Dr. C. Plowe [41], with minor modifications. The nested-PCR included the following fragments of each gene: pfdhfr (108/164, 51/59), pfdhps (400 and 500), pfmdr1 (86/1246) and pfcrt (76). PCR products were separated with electrophoresis on a $2 \%$ agarose gel, stained with Pronasafe (Pronadisa, Spain), identified based on the size fragment and visualized under an ultraviolet transilluminator. The amplification fragments were digested with different restriction enzymes to analyse restriction-fragment length polymorphisms (RFLPs). Each mutation point in each of the genes requires a different enzyme (New England BiolabsR Inc.) to determine whether or not there is a mutation at that position. Each such enzyme was used according to the manufacturer's recommendations. The haplotypes of pfdhfr and pfdhps genes were classified as partially resistant (IRNG). fully resistant (IRNGE) or super resistant (IRNGEG) [18]. The haplotypes of the other genes studied comprised one double mutation in a single gene: $86 \mathrm{Y} / 1246 \mathrm{Y}$ pfmdr1 and a combination of two single mutations in different genes: $86 \mathrm{Y}$ pfmdr1 + 76T pfcrt.

3) Nested PCR and Sequencing of pfk13 gene: the nested PCR protocol described by Ariey et al. [29,42] was used, with some modifications for our laboratory. Polymerase HotStart $(5 \mathrm{U} / \mathrm{mL}$ ) (Biotools, Spain), at a final concentration of $0.028 \mathrm{U} / \mathrm{mL}$, was used to standardize this PCR protocol. For the first PCR, $5 \mathrm{~mL}$ of genomic DNA was used, along with $0.25 \mathrm{mM}$ (final concentration) of each primer: K13-PCR-F (5'GGGAATCTGGTGGTAACAGC-3') / K13-PCR-R (5'-CGGAGTGACCAAATCTGGGA-3'). The volume of the PCR mix was $25 \mathrm{~mL}$. The second PCR (nested) was performed with $0.25 \mathrm{mM}$ (final concentration) of each primer: K13-N1-F (5'-GCCTTGTTGAAAGAAGCAGA-3') / K13-N1-R (5'GCCAAGCTGCCATTCATTTG-3'), with a final volume of the PCR mix of $50 \mathrm{~mL}$. After the second PCR, an electrophoresis on $2 \%$ agarose gel stained with Pronasafe (Pronadisa, Spain) was carried out. The estimated size of the amplification fragment is $+/-850 \mathrm{bp}$.

The PCR products were purified using llustra exoprostar 1-step (GE Healthcare Life Sciences) in accordance with the manufacturer's instructions. Samples were sequenced from both directions using the forward and reverse primers in the second PCR (K13-N1-F/ K13-N1-R) at a concentration of $6 \mathrm{pmol} / \mathrm{mL}$, using a standard dye terminator (Big Dye Terminator v3.1 Cycle Sequencing kit) in an ABI PRISM $3730 \mathrm{XL}$ Analyser. Sequences were compared with the Genebank database using BLAST (Basic Local Alignment Search Tool) [43], to check that the pfk13 gene had been correctly sequenced.

To find new mutations and validated mutations in the $p f k 13$ gene related to resistance to artemisinin derivatives, the sequence of $P f k 13$ gene 3D7 clone (PF3D7_1343700 kelch protein propeller domain) was compared with all the sequences obtained from each sample using BioEdit 7.2 software.

\section{Data analysis}

The prevalence of mutations and haplotypes was calculated for each group of samples, and changes in the prevalence of mutations and haplotypes over time were compared using $X^{2}$ statistics or Fisher's exact test, as appropriate. Logistic regressions were plotted to determine temporal trends in haplotypes, with the statistical significance being assessed using the Man-Kendall trend test. The odds ratio (OR) was used to represent the relative changes between sample groups for the different years included in the study. All statistical tests were performed at a significance level of $5 \%(\mathrm{p}$-value $<0.05)$ and $95 \%$ confidence interval $(\mathrm{Cl})$. Statistical data analysis was conducted using the R 4.0 .0 software package

\section{Results}

A total of 1223 samples obtained from patients with uncomplicated malaria between 1999 and 2019 were analysed in this study: 1999 ( $n=60)$, $2001(n=102), 2004 / 5(n=262), 2006(n=158), 2011(n=163), 2013(n=170), 2016(n=169)$ and $2019(n=139)$. All samples were positive for $P$. falciparum by NM-PCR, and no mixed infection was detected.

\section{Haplotypes in pfdhfrand pfdhps}

SNPs in Pfdhfrand pfdhps genes: considering SNPs individually, it was observed that the frequency of the most prevalent mutations in pfdhfr, namely $511,59 \mathrm{R}$ and $108 \mathrm{~N}$, increased from $96.6 \%, 93.3 \%$ and $93.3 \%$ in 1999 , to $97.1 \%, 94.2 \%$ and $100 \%$, respectively, in 2019 . When the frequency reaches $100 \%$, it can be said that the parasite population has been fixed. Significant differences were detected for pfdhfr mutations when comparing the increase in the frequencies of the mutation at position $108 \mathrm{~N}$ between 1999 and $2019(p=0.002)$. The frequencies of these SNPs were found to increase over time when the frequencies of all years included in the study were taken into account, with significant differences being observed (Table 2).

SNPs detected in pfdhfr and pfdhps genes over the years

Page 5/20 


\begin{tabular}{|c|c|c|c|c|c|c|c|c|c|c|c|c|}
\hline & 511 & & $59 R$ & & $108 \mathrm{~N}$ & & 437G & & $540 \mathrm{E}$ & & $581 G$ & \\
\hline $\begin{array}{l}\text { Year } \\
(\mathrm{N})\end{array}$ & $\begin{array}{l}N \\
(\%)\end{array}$ & $95 \% \mathrm{Cl}$ & $\begin{array}{l}N \\
(\%)\end{array}$ & $\begin{array}{l}95 \% \\
\mathrm{Cl}\end{array}$ & $\begin{array}{l}\mathrm{N} \\
(\%)\end{array}$ & $95 \% \mathrm{Cl}$ & $\begin{array}{l}\mathrm{N} \\
(\%)\end{array}$ & $95 \% \mathrm{Cl}$ & $\begin{array}{l}N \\
(\%)\end{array}$ & $95 \% \mathrm{Cl}$ & $\begin{array}{l}\mathrm{N} \\
(\%)\end{array}$ & $95 \% \mathrm{Cl}$ \\
\hline $1999(\mathrm{~N}=60)$ & $\begin{array}{l}51 \\
(58 \%)\end{array}$ & $\begin{array}{l}88.64- \\
99.08\end{array}$ & $\begin{array}{l}56 \\
(93.3 \%)\end{array}$ & $\begin{array}{l}84.07- \\
97.38\end{array}$ & $\begin{array}{l}56 \\
(93.3 \%)\end{array}$ & $\begin{array}{l}88.64- \\
99.08\end{array}$ & $\begin{array}{l}30 \\
(50 \%)\end{array}$ & $\begin{array}{l}37.74- \\
62.24\end{array}$ & $\begin{array}{l}4 \\
(6.6 \%)\end{array}$ & $\begin{array}{l}2.62- \\
15.93\end{array}$ & $\begin{array}{l}3 \\
(5 \%)\end{array}$ & $\begin{array}{l}1.71- \\
13-70\end{array}$ \\
\hline $2001(\mathrm{~N}=102)$ & $\begin{array}{l}95 \\
(93.1 \%)\end{array}$ & $\begin{array}{l}86.51- \\
96.64\end{array}$ & $\begin{array}{l}88 \\
(86.3 \%)\end{array}$ & $\begin{array}{l}78.27- \\
91.64\end{array}$ & $\begin{array}{l}83 \\
(81.4 \%)\end{array}$ & $\begin{array}{l}72.73- \\
87.74\end{array}$ & $\begin{array}{l}62 \\
(60.7 \%)\end{array}$ & $\begin{array}{l}51.08- \\
69.70\end{array}$ & 0 & $0-3.63$ & 0 & $0-3.63$ \\
\hline $2004 / 5(N=262)$ & $\begin{array}{l}255 \\
(93.3 \%)\end{array}$ & $\begin{array}{l}94.59- \\
98.70\end{array}$ & $\begin{array}{l}259 \\
(98.8 \%)\end{array}$ & $\begin{array}{l}96.69- \\
99.61\end{array}$ & $\begin{array}{l}257 \\
(98.1 \%)\end{array}$ & $\begin{array}{l}95.61- \\
99.18\end{array}$ & $\begin{array}{l}158 \\
(60.3 \%)\end{array}$ & $\begin{array}{l}54.27- \\
66.04\end{array}$ & 0 & $0-3.63$ & 0 & $0-3.63$ \\
\hline $2006(N=158)$ & $\begin{array}{l}150 \\
(94.9 \%)\end{array}$ & $\begin{array}{l}90.33- \\
97.41\end{array}$ & $\begin{array}{l}151 \\
(95.5 \%)\end{array}$ & $\begin{array}{l}91.14- \\
97.84\end{array}$ & $\begin{array}{l}158 \\
(100 \%)\end{array}$ & $\begin{array}{l}97.63- \\
100\end{array}$ & $\begin{array}{l}44 \\
(27.8 \%)\end{array}$ & $\begin{array}{l}21.45- \\
35.3\end{array}$ & $\begin{array}{l}4 \\
(2.5 \%)\end{array}$ & $\begin{array}{l}0.99- \\
6.33\end{array}$ & 0 & $0-2.37$ \\
\hline $2011(\mathrm{~N}=163)$ & $\begin{array}{l}159 \\
(97.5 \%)\end{array}$ & $\begin{array}{l}93.86- \\
99.04\end{array}$ & $\begin{array}{l}159 \\
(97.5 \%)\end{array}$ & $\begin{array}{l}93.86- \\
99.04\end{array}$ & $\begin{array}{l}163 \\
(100 \%)\end{array}$ & $\begin{array}{l}97.7- \\
100\end{array}$ & $\begin{array}{l}136 \\
(93.4 \%)\end{array}$ & $\begin{array}{l}76.97- \\
88.36\end{array}$ & $\begin{array}{l}9 \\
(5.5 \%)\end{array}$ & $\begin{array}{l}2.93- \\
10.16\end{array}$ & $\begin{array}{l}3 \\
(1.8 \%)\end{array}$ & $\begin{array}{l}0.63- \\
5.27\end{array}$ \\
\hline $2013(\mathrm{~N}=170)$ & $\begin{array}{l}168 \\
(98.8 \%)\end{array}$ & $\begin{array}{l}95.81- \\
99.68\end{array}$ & $\begin{array}{l}167 \\
(98.2 \%)\end{array}$ & $\begin{array}{l}94.94- \\
99.4\end{array}$ & $\begin{array}{l}168 \\
(98.8 \%)\end{array}$ & $\begin{array}{l}95.81- \\
99.68\end{array}$ & $\begin{array}{l}149 \\
(87.6 \%)\end{array}$ & $\begin{array}{l}81.85- \\
91.78\end{array}$ & $\begin{array}{l}26 \\
(15.3 \%)\end{array}$ & $\begin{array}{l}10.66- \\
21.47\end{array}$ & $\begin{array}{l}1 \\
(0.58 \%)\end{array}$ & $\begin{array}{l}0.10- \\
3.26\end{array}$ \\
\hline $2016(\mathrm{~N}=169)$ & $\begin{array}{l}169 \\
(100 \%)\end{array}$ & $\begin{array}{l}97.78- \\
100\end{array}$ & $\begin{array}{l}149 \\
(88.2 \%)\end{array}$ & $\begin{array}{l}82.43- \\
92.21\end{array}$ & $\begin{array}{l}168 \\
(98.8 \%)\end{array}$ & $\begin{array}{l}95.81- \\
99.68\end{array}$ & $\begin{array}{l}156 \\
(92.3 \%)\end{array}$ & $\begin{array}{l}87.29- \\
95.45\end{array}$ & $\begin{array}{l}23 \\
(13.6 \%)\end{array}$ & $\begin{array}{l}9.24- \\
19.59\end{array}$ & $\begin{array}{l}5 \\
(3 \%)\end{array}$ & $\begin{array}{l}1.27- \\
6.74\end{array}$ \\
\hline 2019 (N=139) & $\begin{array}{l}135 \\
(97.1 \%)\end{array}$ & $\begin{array}{l}92.83- \\
98.88\end{array}$ & $\begin{array}{l}131 \\
(94.2 \%)\end{array}$ & $\begin{array}{l}89.05- \\
97.06\end{array}$ & $\begin{array}{l}139 \\
(100 \%)\end{array}$ & $\begin{array}{l}97.31- \\
100\end{array}$ & $\begin{array}{l}130 \\
(93.5 \%)\end{array}$ & $\begin{array}{l}88.15- \\
96.56\end{array}$ & $\begin{array}{l}51 \\
(36.6 \%)\end{array}$ & $\begin{array}{l}29.14- \\
44.96\end{array}$ & $\begin{array}{l}2 \\
(1.4 \%)\end{array}$ & $\begin{array}{l}0.4- \\
5.09\end{array}$ \\
\hline$p$-value & $4.9 e-7$ & & 7e-8 & & 0 & & 0 & & 0 & & 0.0053 & \\
\hline
\end{tabular}

Table 2.- All SNPs detected in pfdhfr and pfdhps in the different years included in the study are described in the table. Frequencies, $95 \% \mathrm{Cls}$ and p-values are indicated. $\leq 0.05$ is taken as significance value

The most important increase detected for the pfdhps gene was in 437G, which increased significantly from a frequency of $50 \%$ in 1999 to $93.5 \%$ in $2019(p=0.000)$. The frequency of $540 \mathrm{E}$ also increased, from $6.6 \%$ in 1999 to $36.6 \%$ in 2019 , but it remains far below the threshold frequency $(50 \%)$ considered to indicate a lack of effectiveness of the SP in the IPT. In contrast, the frequency of the $581 \mathrm{G}$ mutation decreased from $5 \%$ in 1999 to $1.4 \%$ in 2019 , although this decrease is not significant. The frequencies of the SNPs 540E and 581G in 2019 were $36.6 \%$ and $1.4 \%$, respectively, values which are almost three times higher than that detected in 2016 for $540 \mathrm{E}$ but almost three times lower for $581 \mathrm{G}$. The increase in frequencies over time was clear, with the exception of 581G, which decreased from $3 \%$ in 2016 to $1.4 \%$ in 2019; the frequency of each SNP detected in each of the years included in the study is detailed in Table 1.

Haplotypes pfdhfr + pfdhps: combinations of the SNPs in both genes (pfdhfr and pfdhps) were classified into three haplotypes: partially resistant, fully resistant and super resistant [18] as described in the materials and methods section. A partially resistant haplotype (IRNG) with a frequency of $43.3 \%$ appeared in 1999 , subsequently increasing gradually over the years to reach a maximum of $86.3 \%$ in 2019 . However, a slight decrease in frequency to $81 \%$ was observed in 2016, (Table 3). Significant differences can be observed when all years are compared $(p=0.00)$. The fully resistant (IRNGE) haplotype appears with a frequency of $8.3 \%$ in 1999 , subsequently increasing to $11.2 \%$ in 2013 and $11.8 \%$ in 2016 . However, this haplotype showed a sharp increase to $30.2 \%$ in 2019, an increase of almost three times the frequency detected in 2016 in only two years. Significant differences were detected between the different years, from 1999 to 2019 ( $p=0$; Table 3). The super resistant haplotype (IRNGEG) was not detected in 1999, 2001, 2006, 2011, and 2019 but was detected in 2004/5, 2013 and 2016 at a low frequency of 0.39\%, 0.6\% and $1.7 \%$ respectively (Table 3 ). Table 3 clearly shows that the frequencies of the different haplotypes have changed significantly over the years. Importantly, the super-resistant haplotype was not detected in 2019, so continued surveillance may ensure that SP remains useful for IPT.

\section{Frequency of haplotypes over the years}




\begin{tabular}{|c|c|c|c|c|c|c|}
\hline & $\begin{array}{l}\text { Partially resist } \\
\text { (IRNG) }\end{array}$ & & $\begin{array}{l}\text { Fully resi } \\
\text { (IRNGE) }\end{array}$ & & $\begin{array}{l}\text { Super res } \\
\text { (IRNGEG }\end{array}$ & \\
\hline $\begin{array}{l}\text { Year } \\
(\mathrm{N})\end{array}$ & $\begin{array}{l}\mathrm{N} \\
\text { (Freq.) }\end{array}$ & Cl95\% & $\begin{array}{l}\mathrm{N} \\
\text { (Freq.) }\end{array}$ & Cl95\% & $\begin{array}{l}\mathrm{N} \\
\text { (Freq.) }\end{array}$ & $\mathrm{Cl} 95 \%$ \\
\hline $\begin{array}{l}1999 \\
(60)\end{array}$ & $\begin{array}{l}26 \\
(43.3 \%)\end{array}$ & $31.57-55.9$ & $\begin{array}{l}5 \\
(8.3 \%)\end{array}$ & $3.61-18.07$ & 0 & $0-6.02$ \\
\hline $\begin{array}{l}2001 \\
(102)\end{array}$ & $\begin{array}{l}44 \\
(43.1 \%)\end{array}$ & $33.95-52.83$ & 0 & $0-3.63$ & 0 & $0-3.63$ \\
\hline $\begin{array}{l}2004 / 5 \\
(262)\end{array}$ & $\begin{array}{l}149 \\
(56.8 \%)\end{array}$ & $50.8-62.9$ & $\begin{array}{l}10 \\
(3.9 \%)\end{array}$ & $2.09-6.88$ & $\begin{array}{l}1 \\
(0.39 \%)\end{array}$ & $7 e-02-2.13$ \\
\hline $\begin{array}{l}2006 \\
(158)\end{array}$ & $\begin{array}{l}99 \\
(62.6 \%)\end{array}$ & $54.9-69.8$ & $\begin{array}{l}3 \\
(1.89 \%)\end{array}$ & $0.65-5.43$ & 0 & $0-2.37$ \\
\hline $\begin{array}{l}2011 \\
(163)\end{array}$ & $130(79.75 \%)$ & $72.93-85.21$ & $\begin{array}{l}6 \\
(3.7 \%)\end{array}$ & $1.70-7.80$ & 0 & $0-2.3$ \\
\hline $\begin{array}{l}2013 \\
(170)\end{array}$ & $\begin{array}{l}145 \\
(85.2 \%)\end{array}$ & 79.19-89.84 & $\begin{array}{l}19 \\
(11.2 \%)\end{array}$ & $7.27-16.8$ & $\begin{array}{l}1 \\
(0.6 \%)\end{array}$ & $0.10-3.26$ \\
\hline $\begin{array}{l}2016 \\
(169)\end{array}$ & $\begin{array}{l}137 \\
(81.1 \%)\end{array}$ & 74.49-86.26 & $\begin{array}{l}20 \\
(11.8 \%)\end{array}$ & $7.79-17.57$ & $\begin{array}{l}3 \\
(1.7 \%)\end{array}$ & $0.61-5.09$ \\
\hline $\begin{array}{l}2019 \\
(139)\end{array}$ & $\begin{array}{l}120 \\
(86.3 \%)\end{array}$ & 79.64-91.07 & $\begin{array}{l}42 \\
(30.2 \%)\end{array}$ & $23.20-38.30$ & 0 & $0-2.69$ \\
\hline$p$-value & 0 & & 0 & & 0.161 & \\
\hline
\end{tabular}

Table-3.- It is shown the frequency of each of the three haplotypes into which the combined mutations of the pfdhfr+pfdhps genes have been classified. It is shown for each of the years included in the study. Haplotypes: partially resistant 511/59R/108N/437G (IRNG), fully resistant $51 \mathrm{I} / 59 \mathrm{R} / 108 \mathrm{~N} / 437 \mathrm{G} / 540 \mathrm{E}$ (IRNGE) and super resistant 51I/59R/108N/437G/540E/581G. N: number of samples analysed. $\leq 0.05$ is taken as significance value

The logistic regression showed that, from 2001 to 2019, the probability of finding partially resistant haplotypes increased significantly in most years. This upward trend was confirmed using the Man-Kendall trend test (tau $=0.857, \mathrm{p}$-value $=0.004$ ). The odds of finding partially and fully resistant haplotypes was found to increase gradually over time, with the exception of 2016, reaching a maximum in 2019 (OR $=3.53$ for IRNG and $\mathrm{OR}=3.72$ for IRNGE (Figure 2).

Figure 3 also shows that the increase of the fully resistant haplotype in 2019 is at the expense of its partially resistant counterpart. This means that there was no significant increase in new partially resistant cases, simply that these quadruple mutant parasites are acquiring the fifth mutation. Encouragingly, the super resistant haplotype remains at only a low frequency.

\section{Haplotypes in pfmdr1 and pfcrt.}

All the SNPs related with resistance to CQ or AQ decreased in frequency from 1999 to 2019 (Table 4).

Pfmdr1 gene: the frequency of the 86 Y mutation was found to increase from 1999 to 2001 , when it reached a maximum (96.1\%), subsequently decreasing until 2019 , when it was detected at a frequency of $13.6 \%$. Significant differences were detected when comparing the evolution between 1999 and $2019(p=0.00)$. A similar evolution was detected for the other point mutation (1246Y), the frequency of which reached a maximum in 2001 (23.5\%), subsequently decreasing until it could no longer be detected in 2016. The maximum frequency for the haplotype 86Y/1246Y (YY) was also seen in 2001 (20.5\%), and this haplotype could also not be detected in 2016 (Table 4).

Pfcrt gene: It is important to note that a frequency peak was detected in 2001 in all cases, after which frequencies began to fall. The SNPs $86 \mathrm{Y}$ (pfmdr1) and 76T (pfcrt), were still detected in 2019, although at a low frequency, whereas 1246 (pfmdr1) was no longer detected in 2019. The frequency of the mutation at this point in the gene (76T) was more frequent than mutations in pfmdr1, although their evolution was similar. Thus, it appears with a frequency of $71.6 \%$ in 1999 , peaking in 2001 (85.3\%), from where its presence decreased to a minimum of $2.8 \%$ in 2019 (Table 4). 
Frequencies of SNPs and haplotypes in pfmdr1 and pfcrt genes over the years

\begin{tabular}{|c|c|c|c|c|c|c|c|c|c|c|}
\hline \multirow{4}{*}{$\begin{array}{l}\text { Year } \\
(\mathrm{N})\end{array}$} & \multirow{2}{*}{\multicolumn{2}{|c|}{$\begin{array}{l}\text { pfmdr1 } \\
86 Y\end{array}$}} & \multirow{2}{*}{\multicolumn{2}{|c|}{$1246 Y$}} & \multirow{2}{*}{\multicolumn{2}{|c|}{$86 Y / 1246 Y$}} & \multirow{2}{*}{\multicolumn{2}{|c|}{$\begin{array}{l}\text { pfcrt } \\
76 \mathrm{~T}\end{array}$}} & \multicolumn{2}{|c|}{$p f m d r 1+p f c r t$} \\
\hline & & & & & & & & & $86 Y / 76 T$ & \\
\hline & $\mathbf{N}$ & $95 \% \mathrm{Cl}$ & $\mathbf{N}$ & $95 \% \mathrm{Cl}$ & $\mathbf{N}$ & $95 \% \mathrm{Cl}$ & $\mathbf{N}$ & $95 \% \mathrm{Cl}$ & $\mathbf{N}$ & $95 \mathrm{Cl}$ \\
\hline & $(\%)$ & & $(\%)$ & & $(\%)$ & & $(\%)$ & & $(\%)$ & \\
\hline $\begin{array}{l}1999 \\
(60)\end{array}$ & $\begin{array}{l}37 \\
(61.6 \%)\end{array}$ & $\begin{array}{l}49.02- \\
72.91\end{array}$ & $\begin{array}{l}4 \\
(6.6 \%)\end{array}$ & $2.62-15.93$ & $\begin{array}{l}1 \\
(1.6 \%)\end{array}$ & $0.29-8.86$ & $\begin{array}{l}43 \\
(71.6 \%)\end{array}$ & $\begin{array}{l}59.23- \\
81.49\end{array}$ & $\begin{array}{l}32 \\
(53.3 \%)\end{array}$ & $\begin{array}{l}40.89- \\
65.37\end{array}$ \\
\hline $\begin{array}{l}2001 \\
(102)\end{array}$ & $\begin{array}{l}98 \\
(96.1 \%)\end{array}$ & $\begin{array}{l}90.35- \\
98.46\end{array}$ & $\begin{array}{l}24 \\
(23.5 \%)\end{array}$ & $\begin{array}{l}16.35- \\
32.63\end{array}$ & $\begin{array}{l}21 \\
(20.5 \%)\end{array}$ & $\begin{array}{l}13.88- \\
29.43\end{array}$ & $\begin{array}{l}87 \\
(85.3 \%)\end{array}$ & $\begin{array}{l}77.15- \\
90.88\end{array}$ & $\begin{array}{l}84 \\
(82.3 \%)\end{array}$ & $\begin{array}{l}73.82- \\
88.54\end{array}$ \\
\hline $\begin{array}{l}2004 / 5 \\
(262)\end{array}$ & $\begin{array}{l}220 \\
(83.9 \%)\end{array}$ & $\begin{array}{l}\text { 79.04- } \\
87.92\end{array}$ & $\begin{array}{l}3 \\
(1.1 \%)\end{array}$ & $0.39-3.31$ & $\begin{array}{l}3 \\
(1.1 \%)\end{array}$ & $0.39-3.31$ & $\begin{array}{l}200 \\
(76.3 \%)\end{array}$ & $\begin{array}{l}\text { 70.83- } \\
81.08\end{array}$ & $\begin{array}{l}170 \\
(64.8 \%)\end{array}$ & $\begin{array}{l}59.93- \\
70.41\end{array}$ \\
\hline $\begin{array}{l}2006 \\
(158)\end{array}$ & $\begin{array}{l}113 \\
(71.5 \%)\end{array}$ & $\begin{array}{l}64.04- \\
77.98\end{array}$ & $\begin{array}{l}1 \\
(0.6 \%)\end{array}$ & $0.11-3.5$ & $\begin{array}{l}1 \\
(0.6 \%)\end{array}$ & $0.11-3.5$ & $\begin{array}{l}107 \\
(67.7 \%)\end{array}$ & $\begin{array}{l}\text { 60.09- } \\
74.52\end{array}$ & $\begin{array}{l}76 \\
(48.1 \%)\end{array}$ & $\begin{array}{l}40.45- \\
55.84\end{array}$ \\
\hline $\begin{array}{l}2011 \\
(163)\end{array}$ & $\begin{array}{l}114 \\
(69.9 \%)\end{array}$ & $\begin{array}{l}62.51- \\
76.45\end{array}$ & 0 & $0-2.30$ & 0 & $0-2.30$ & $\begin{array}{l}114 \\
(69.9 \%)\end{array}$ & $\begin{array}{l}62.51- \\
76.45\end{array}$ & $\begin{array}{l}78 \\
(47.8 \%)\end{array}$ & $\begin{array}{l}40.32- \\
55.48\end{array}$ \\
\hline $\begin{array}{l}2013 \\
(170)\end{array}$ & $\begin{array}{l}125 \\
(73.5 \%)\end{array}$ & $\begin{array}{l}66.43- \\
79.59\end{array}$ & $\begin{array}{l}3 \\
(1.7 \%)\end{array}$ & $0.6-5.06$ & $\begin{array}{l}1 \\
(0.6 \%)\end{array}$ & $0.10-3.26$ & $\begin{array}{l}109 \\
(64.1 \%)\end{array}$ & $\begin{array}{l}56.67- \\
70.94\end{array}$ & $\begin{array}{l}81 \\
(47.6 \%)\end{array}$ & $\begin{array}{l}\text { 40.27- } \\
55.12\end{array}$ \\
\hline $\begin{array}{l}2016 \\
(169)\end{array}$ & $\begin{array}{l}47 \\
(27.8 \%)\end{array}$ & $21.61-35$ & 0 & $0-2.22$ & 0 & $0-2.22$ & $\begin{array}{l}33 \\
(19.5 \%)\end{array}$ & $\begin{array}{l}14.26- \\
26.15\end{array}$ & $\begin{array}{l}12 \\
(7.1 \%)\end{array}$ & 4.11-12 \\
\hline $\begin{array}{l}2019 \\
(n 139)\end{array}$ & $\begin{array}{l}19 \\
(13.6 \%)\end{array}$ & $8.93-20.36$ & 0 & $0-2.29$ & 0 & $0-2.29$ & $\begin{array}{l}4 \\
(2.8 \%)\end{array}$ & $1.12-7.17$ & 0 & $0-2.29$ \\
\hline p-value & 0 & & 0 & & 0 & & 0 & & 0 & \\
\hline
\end{tabular}

Table 4.- Frequencies of SNPs detected in both $p f m d r 1$ and $p f c r t$ genes, as well as frequencies of haplotypes both within $p f m d r 1$ (86Y/1246Y) and the combination of pfmdr1 and pfcrt $(86 \mathrm{Y} / 76 \mathrm{~T})$. It is detailed for each year included in the study and is given the value of $95 \% \mathrm{Cl}$ and $\mathrm{p}$ value. $\leq 0.05$ is taken as significance value

Figure 4, shows that many mutant populations are decreasing over time, while the wild populations are increasing, probably due to elimination of the selective pressure exerted by CQ since its withdrawal from use in 2001.

Similarly, the haplotype formed by the mutations in 86Y/76T (YT) increased from 1999 to 2001, when a maximum frequency of $82.3 \%$ was detected. From this point, its frequency decreased significantly until 2019, when it could no longer be detected (OR=0.21, $\mathrm{p}$-value $<0.05)$. The

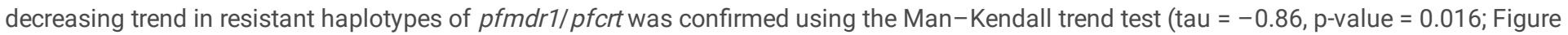
5).

\section{Haplotypes in pfk13}

Pfk13. Sequences for the K13-propeller domain were generated successfully for all the samples analysed in this study. Nearly all samples (1209/1223, 98.8\%) were found to contain a wild-type allele. In contrast, SNPs were detected in only 13 samples (13/1223, $1.06 \%)$, and one sample contained two SNPs. As such, 13 samples contained a total of 14 SNPs. The frequency of samples containing mutations (synonymous and non-synonymous) over the years was $0.98 \%$ in $2001,0.76 \%$ in $2004 / 5,0.6 \%$ in $2006,1.76 \%$ in 2013 and $5 \%$ in 2019 (Table 5 ).

A total of 14 SNPs were detected, with six of these being synonymous $(6 / 14 ; 42.8 \%)$ and eight non-synonymous (8/14; $57 \%)$. The six synonymous k13 mutations were found in positions G612G (2001), N645N (2004/5), L663L (2006), C469C (2013) and two C469C (2019). The eight non-synonymous mutations detected in pfk13 gene were A569V in 2004/5, V510A and A578S in 2013, and C532Y, G638R, G544R, E668L and D464N in 2019. The highest number of mutations was detected in 2019 , and most of the mutations detected were non-synonymous.

The synonymous mutation C469C was detected once in 2013 and twice in 2019, and the synonymous mutation E612E was detected in 2001. All mutations detected are shown in detail in Table 5. 


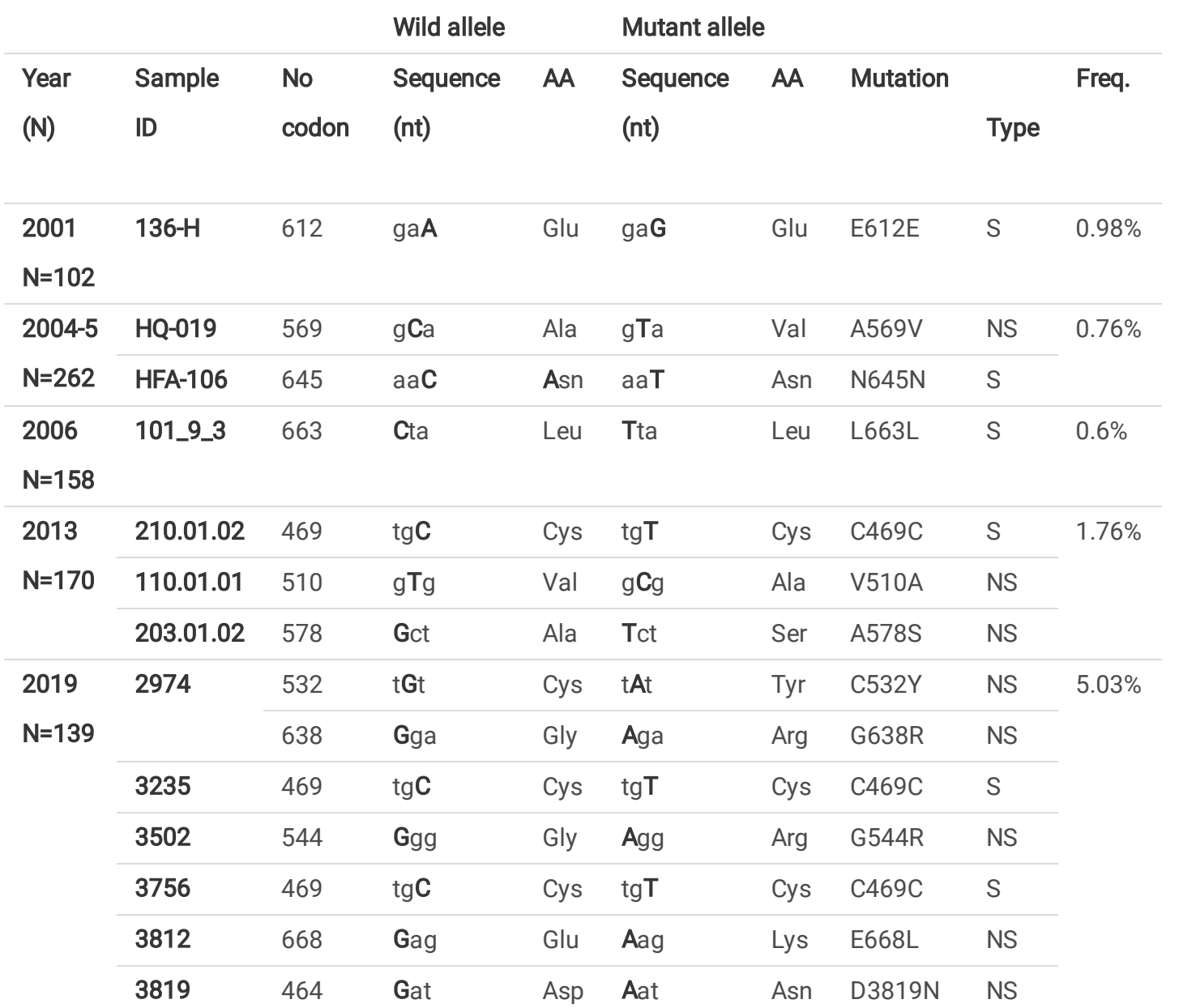

Tabla 5.- SNPs detected in pfk13 gene after sequencing and its study. The type of mutation detected, synonymous or non-synonymous is indicated. ID: identification; AA: amino acid, nt: nucleotide; Freq.: frequency. Capital letter in the codon sequence indicates the muted nucleotide; S: Synonymous; NS: Non-Synonymous. The nucleotide that changes with the mutation is shown in capital letters and in bold.

In a sample from 2019 in which a non-synonymous mutation (GGA to GAA; G592E) was detected, sequence analysis suggests that this could be a mixture of $P$. falciparum populations (wild and mutant parasites; Figure 6).

\section{Discussion}

A large number of SNPs related to resistance to different antimalarial drugs that have been used as first-line or preventive treatment have been evaluated in this study. Evolution of resistance to SP (pfdhfr, pfdhps), CQ and AQ (pfmdr1 and pfcrt) and artemisinin ( $p f k 13)$ has been assessed taking into account the changes in public health treatment strategies.

Normally, when a country withdraws a given treatment due to drug resistance, the presence of sensitive parasites increases with respect to the resistant population over a given time period. However, it should also be borne in mind that misuse of treatments and the great plasticity of the parasite can make it possible for mutant parasites to increase and spread.

Numerous efficacy studies of antimalarial drugs were carried out in Equatorial Guinea between 1999 and 2019. Moreover, first-line treatments changed over time until 2008, when ACTs were introduced, the first being ASAQ. From 1990 to 1992, in vitro studies [44] found that CQ had a resistance of $16 \%$ and SP resistance was not particularly high ( $>5 \%$ ), thus meaning that SP could be used as a treatment in Equatorial Guinea. A subsequent in vivo study assessing the evolution of CQ and SP efficacy from 1992 to 1999 [45] found that CQ had 40\% resistance and SP had $16 \%$ resistance, therefore CQ and SP were not used as treatment for malaria after 1999. Although CQ was withdrawn as a treatment in 1999 , it can be seen that the frequency of resistance-related mutations in pfmd1, pfcrt and the combination pfmdr1 + pfcrt reached a maximum in 2001, after which it started to decrease. This may be because it is estimated that it usually takes two years for the parasite to show any change in response to treatment, which is why efficacy studies are conducted at least every two years. However, this may also be explained by the delay in implementing a uniform treatment strategy throughout the country. Resistance to CQ is linked to a mutation at codon 76 of pfcrt, which has proven to be the chief determinant of CQ resistance [46]. As such, the decreasing trend in this mutation and the haplotype $86 \mathrm{Y} / 76 \mathrm{~T}$ indicates 
that the withdrawal of CQ as a treatment was effective and has been maintained over time. As the selective pressure exerted by CQ on the parasite population has been removed, the frequency of the wild-type population has increased with respect to the mutant population. As noted by Achieng et al [47], what we would expect over time is a greater increase of wild pfcrt K76 and pfmdr1 N86 due to the longer withdrawal time of $\mathrm{CQ}$ and distribution of $\mathrm{AL}$ as treatment. It would therefore be of interest to revisit the mutational profile for the $p f m d r 1$ and $p f c r t$ genes of $P$. falciparum over a period of at least two years to see how this changed in the presence of AL.

The downward trend in these mutations means that the susceptible population is higher than the mutant population, thus meaning that the efficacy of other antimalarial drugs such as $\mathrm{AQ}$ and $\mathrm{MQ}$ is assured. However, other studies have shown that the reintroduction of CQ treatment might rapidly lead to the selection of mutant populations again [48].

Likewise, selection of the wild-type K76 codon in the $P$. falciparum CQ resistance transporter gene ( $p f c r t$ ) has been associated with pressure from AL treatment (first-line of treatment in Equatorial Guinea from 2020) in a number of studies [49-54]. Indeed, dramatic increases in the prevalence of wild-type pfcrt K76 and pfmdr1 N86 have been associated with discontinuation of CQ and deployment of AL in western Kenya, although AL continued to be effective with these changes [47]. In Equatorial Guinea, there has been an evolution in this direction since 1999, i.e. a decrease in mutants in favour of an increase in wild populations. Thus, the wild genotype pfmdr1 N86 had a frequency of $86 \%$, whereas that for pfcrt K76 was $100 \%$, in 2019.

Although it was known from previous studies that there was 25\% resistance to SP in Equatorial Guinea since 1999 [45], it was still used as a treatment, either alone or in combination, until 2008. In 2005 [3] a new study in which the combinations ASSP and ASAQ were tested was carried out in order to have two treatment alternatives in combination. Despite its slightly yet constantly increasing trend in resistance, SP was never discontinued as a treatment. These combinations were used in Equatorial Guinea from 2003 until 2008, when ASAQ, the first ACTs used in that country, was introduced. The use of SP in combination with AQ and AS has been widespread for many years, with the serious harm to resistance that its use entails. Accordingly, this has led to an increase in genetically resistant populations, as can be seen in the results section, and we can even see some SNPs that are fixed in the population, as is the case of pfdhfr $108 \mathrm{~N}$, which has a frequency of $100 \%$. The use of these combinations has created a scenario with selective pressure in which some of the mutations not only increase and spread but also become fixed in the parasite population.

Importantly, the 164L mutation in pfdhfr, which is related to a significant resistance to SP [55], has not been detected in any of the years studied in this study. However, this mutation was previously detected in Equatorial Guinea, by us, in samples from 2013 [56]. In light of the above, the data obtained from the analysis of $p f d h f r+p f d h p s$ haplotypes over time reveal that there has been no real or total withdrawal of SP as a treatment. It can be seen that the partially resistant (IRNG) and fully resistant (IRNGE) haplotypes have been progressively increasing since 1999, reaching their peak in 2019, whereas the super-resistant ones (IRNGEG) have always had a low trend over time, never exceeding $2 \%$ and not being found in 2019. The data obtained are consistent with previous studies with samples from the island of Bioko, where the partially and fully resistant types were the most common and the frequency of the super-resistant type was very low [57].

Evidence for the misuse of SP in the mainland region of Equatorial Guinea, where it was found that $27.3 \%$ of children had received artemether in monotherapy, $13.8 \%$ SP and only $6.8 \%$ had received the official ACT treatment (ASAQ) [58], supports the hypothesis of the influence of incorrect treatments on the evolution of resistance. This is probably because the official first- and second-line treatments are not available countrywide. As SP is still used as a treatment and has not been reserved only for SP-IPT in the two main populations vulnerable to malaria, namely pregnant women (SP-IPTp) and children under 5 years of age (SP-IPTi), its efficacy has been compromised [17, 59].

Although resistance-related haplotypes to SP exhibit an upward trend, it has been observed that mutations at positions $540 \mathrm{E}$ (36.6\%) and $581 \mathrm{G}$ (1.4\%) are not sufficiently high to jeopardise the use of SP in IPT. Current WHO recommendations suggest that SP-IPTp should be discontinued if the frequency of $540 \mathrm{E}$ exceeds $50 \%$ and that of $581 \mathrm{G}$ exceeds $10 \%$ [57]. Based on current evidence, IPTp and IPTi remain effective in preventing the adverse consequences of malaria on maternal, foetal and infant outcomes in Equatorial Guinea. However, the implementation of control measures in the country should be maintained to avoid the spread of these mutations and the consequent reduction in the efficacy of IPTp.

The data obtained in this study are similar to those observed in countries bordering Equatorial Guinea, such as Cameroon and Gabon. In Gabon [60] for instance, the partially resistant haplotype appeared in 2014 with a frequency of $92.9 \%$ (compared with $85.2 \%$ and $81.1 \%$ in Equatorial Guinea in 2013 and 2016, respectively). Similarly, this haplotype is also the most frequent in Cameroon [61], this same haplotype is also the most frequent. Therefore, it seems that the distribution of parasites with resistant haplotypes to SP is quite homogeneous in the area.

The introduction of ACTS as a treatment for malaria was very effective in mitigating the threat of resistance to antimalarial treatments. In 2006 [5], an efficacy study was carried out to determine the efficacy of ASAQ, the first time that an ACT for treating uncomplicated malaria had been tested in Equatorial Guinea. As a result, ASAQ began to be used as first-line treatment in 2008, when the National Guidelines were changed, and AL as second line. Two years after the introduction of ACTs, in 2010, a new efficacy study was conducted for ASAQ [62] and its efficacy was

Page $10 / 20$ 
found to be $95 \%$, therefore its use as first-line treatment was maintained. However, it was difficult to maintain patient adherence [63] to this treatment due to side effects such as headache, nausea, tinnitus and fatigue. The presence of these side effects, and the lack of adherence to treatment, has led to the use of artemether as monotherapy in some areas of the country. Monotherapy is not permitted by WHO because it may favour the emergence of ART-resistant parasite populations, which could threaten the future efficacy of ACTs in the country.

The last efficacy study carried out in Equatorial Guinea in 2017/2018 [6], showed that the efficacy of ASAQ and AL was close to 95\% and that no ART resistance was detected. Following the completion of this efficacy study, a new National Therapeutic Guideline for malaria was published in January 2020. This new guideline shows a change in the lines of treatment, recommending AL as the first line of treatment and ASAQ as the second, in order to facilitate patient adherence to treatment.

The study of pfk13 gene sequences carried out herein to determine the presence of mutations related to resistance to ART, and therefore to ACTs, allows us to ascertain whether this combination therapy is being used correctly in Equatorial Guinea. The development and spread of ARTresistant $P$. falciparum outside the Greater Mekong Subregion (GMS) poses a great challenge, particularly to sub-Saharan Africa, where in 2020 it accounted for $90 \%$ of global malaria cases and $95 \%$ of malaria deaths [1]. Genetic analysis of the whole genome sequences previously performed showed that the resistant isolates were classified as an African-specific group. This suggests that they may have originated in Africa and not through the migration process from GMS [64].

Current data from this study report a low prevalence (5\%) for pfk13 mutations, both synonymous and non-synonymous, and none of these was among those associated with ART clearance delay in Southeast Asia. The allelic frequencies reported for Central, West and East Africa are generally less than 6\% [65-67]. Our result is within this limit, because the frequency of the pfk13 mutation in Equatorial Guinea has increased in relative terms since 1999, reaching 5\% in 2019. A study conducted in Cameroon, a country bordering Equatorial Guinea, revealed a high mutation rate of $15.1 \%$ for isolates containing at least one non-synonymous mutation [68].

The most common non-synonymous mutation (A578S) observed in Africa was detected in a sample from 2013, as well as in in two samples from the therapeutic study carried out in Equatorial Guinea (2017-2018) [6]. A similar study of pfk13 carried out in Equatorial Guinea detected that $2.04 \%$ of cases exhibited the non-synonymous A578S mutation [69]. The same mutation was detected in the same year (2013) in Cameroon and Gabon [32,60], both of which border the mainland region of Equatorial Guinea. This mutation (578S) was detected in the 2017/18 efficacy study but not in the 2019 samples in the current study [6]. Moreover, it is the most common mutation in Africa, therefore it is likely that if we analysed a larger number of samples from 2019 it would also be detected. The non-synonymous mutation E612K (GAA to AAA) was detected in Cameroon in 2017 [37] and the same mutation appeared in our study, but synonymous (E612E, GAA to GAG), in a sample from 2001. Given that this mutation has been detected as non-synonymous in Cameroon and as synonymous in our study, it could be hypothesised that this point is an area of genetic instability. It could also indicate that this is the first step for a non-synonymous mutation to occur in Equatorial Guinea in the future. One interesting finding is the detection of the synonymous mutation C469C, which appears in one sample from 2013 and in two samples from 2019. It will be interesting to continue characterizing more isolates and to see if this mutation continues to appear, or if its frequency continues to increase over time. Surveillance will have to be established to see if in the future such a synonymous mutation could become non-synonymous and have clinical significance for ACTs resistance.

It is essential to continue to make correct use of the first- and second-line treatments ( $\mathrm{AL}$ and ASAQ respectively) to avoid the appearance of new mutations, and good surveillance is essential to be able to quickly detect possible mutations from SEA that might be introduced into the country and, if they appear, to prevent them from spreading.

Taken together, the low frequencies of pfk13 mutant alleles found in Equatorial Guinea suggest that ART-resistant parasites are not under evolutionary selection in this country, thus reinforcing the assumption that such mutations are rare in Africa. Furthermore, none of the polymorphisms known to be involved in ART resistance in Asia has been associated with ART resistance in Africa. Therefore, local ART-resistant P. falciparum strains may emerge independently in Equatorial Guinea and in the African continent under constant drug pressure from ACT, possible misuse of these drugs if treatment guidelines are not followed, non-adherence to treatment, self-medication and the introduction of counterfeit drugs as is known to be occurring [2].

The effect observed on the evolution of parasites with mutations related to CQ resistance, which have decreased significantly compared to parasites from 20 years ago, indicates that avoiding pharmacological pressure by withdrawing treatment is one of the most important aspects affecting the increase of sensitive parasites compared to resistant parasites. Regarding to mutations in $p f d h f r$ and $p f d h p s$ is important to establish intensive surveillance because the use of SP as a preventive treatment in pregnant women and children under 5 years of age could be at risk. As for ACTs, as recommended by WHO, treatments should only be administered when the presence of the parasite has been identified by a diagnostic method, avoiding unnecessary treatments. Compliance with the National Therapeutic Guidelines for malaria is mandatory to avoid the use of other treatments that have already been withdrawn and are no longer effective. 
All of the above highlights the need for constant surveillance to detect resistance-related mutations early so that we can prevent them from spreading. Consequently, this will ensure that the population receives better health care and that treatment to cure malaria is adequate, as a complete cure is a benefit not only for the patient, but also for the whole community.

\section{Conclusions}

The study of resistance markers allows us to evaluate the efficacy of treatments, and to determine whether there is good adherence to them. These markers also allow us to evaluate how different public health strategies affect the parasite population.

The withdrawal of CQ as a treatment in Equatorial Guinea has been effective over time, as wild-type parasite populations outnumber mutant populations. The 86Y/76T haplotype (pfmdr1 + pfcrt) has declined and could no longer be detected in 2019.

The upward trend observed in SP resistance markers evidence its misuse, either alone or in combination with AS or AQ, in some areas of the country, although it should not have been used as a treatment for a long time now. This keeps the selective pressure of SP in the area, allowing partially and fully SP-resistant haplotypes to be very high. Although, super-resistant haplotypes are not yet at a remarkable frequency, without surveillance they could start to become more prevalent in the population.

As for the pfk13 gene, it can be seen that since the incorporation of ACTs as first-line treatment in 2008, no mutations have been detected in relation to ART resistance. However, it can be seen that there is a greater accumulation of non-synonymous mutations in 2019 compared to years prior to 2008, although these appear to be unrelated to resistance. Taking into account the results of the latest therapeutic efficacy study carried out in Equatorial Guinea (2018), ASAQ and AL have been shown to have a high efficacy for the treatment of uncomplicated malaria.

In light of all the data obtained, the National Malaria Programme must monitor the use of SP in order to reserve it exclusively for IPTs, making its use mandatory and with supervision by the first- and second-line malaria treatment program. To this end, there should be an equal and homogeneous distribution throughout the country, therapeutic efficacy studies every two years, and pfk13 mutational profiling studies to detect possible resistance-related mutations in order to control their spread to other regions. Finally, rapid diagnosis and effective treatment are the basis for malaria control and are therefore essential for ensuring quality health care.

\section{Abbreviations}

- Artemether/ lumefantrine (AL)

- Artemisinina (ART)

- Artemisinin-based combination therapy (ACT)

- Artesunate-amodiaquine (ASAQ)

- Basic Local Alignment Search Tool (BLAST)

- Chloroquine (CQ)

- Chloroquine resistant transporter gene ( $p f c r t)$

- Dihydrofolate reductase gene ( $p f d h f r)$

- Dihydropteroate synthase gene (pfdhps)

- Fully resistant (IRNGE)

- Intermittent preventive treatment (IPT)

- Intermittent preventive treatment in infants (IPTi)

- Intermittent preventive treatment in pregnant woman (IPTp)

- kelch propeller domain on chromosome 13 (pfk13)

- Lumefantrine (L)

- Mefloquine (MQ)

- Nested Multiplex Malaria PCR (NM-PCR)

- P. falciparum multi-drug resistance gene (pfmdr1)

- Partially resistant (IRNG)

- Quinine (Q)

- Single Nucleotide Polymorphism (SNPs)

- Southeast Asia (SEA)

- Sulfadoxine/pyrimethamine (SP) 
- Super resistant (IRNGEG)

- World Health Organization (WHO)

\section{Declarations}

Availability of data and materials': The datasets used and/or analysed during the current study are available from the corresponding author on reasonable request.

Ethics approval and consent to participate: All samples are part of a collection deposited in the sample pool of the Institute of Health Carlos III (ISCIII) of the National Centre of Tropical Medicine. The samples were taken inside of different projects that were carried out in Equatorial Guinea. The Ethics Committee of the ISCIII and the Ministry of Health and Social Welfare of Equatorial Guinea approved these projects.

Consent for publication: All authors agree to the publication of the manuscript, and there are not any competing interests. All authors read and approved the final manuscript.

Competing interests: the authors declare that they have no competing interests.

Funding: The projects where the samples were taken were funded by Spanish Agency for International Cooperation and Development (AECID), ISCIII, Cooperative Research Network on Tropical Diseases (RICET) and by the Strategic Action in Health (Acción Estratégica en Salud) of the Institute of Health Carlos III (Madrid, Spain), project No. TRPY111/2018 (PI17CIII/0016)

Authors' Contributions: PB has carried out the design of the project, principal investigator of the project. PB and IMF have participated in the molecular studies, interpretation and in the statistical analysis of the results and drafting of the manuscript. TTT has participated in the molecular studies. VG, LG, LCG, ARG, RDR and RG, has participated in the molecular studies

PN he is the Project coordinator in the field where the samples have been taken. MR is the Director of the National Malaria Programme and she has facilitated the implementation of activities in the field. $\mathbf{A B}$ he is de Director of the National Centre of Tropical Medicine, he has given permission for the use of the samples from the sample collection held in the custody of the centre and has supported all the work that has been done for this article.

\section{Acknowledgements}

We would like to thank all the people who have worked for 20 years in Equatorial Guinea to collect in various activities the samples that are part of our collection: Dr. Jesús Roche, Dr. Ana Guerra, Dr. Jorge Cano, Dr. Laura Molina, Dr. Pilar Charle, Dr. Maria Romay, Dr. Zaida Herrador. To the National Malaria Programme and the Ministry of Health and Social Welfare of Equatorial Guinea. Above all, to the people of Equatorial Guinea who are always willing to collaborate to try to improve the health of their community.

\section{Author's Information}

Corresponding Author, Pedro Berzosa Díaz (PB), National Centre of Tropical Medicine-Institute of Health Carlos III. pberzosa@isciii.es

Irene Molina de la Fuente (IMF), Department of Biomedicine and Biotechnology University of Alcalá and National Centre of Tropical MedicineInstitute of Health Carlos III. i.molina@edu.uah.es

Thuy-Huong Ta-Tang (TTT), National Centre of Tropical Medicine-Institute of Health Carlos III. TTA@isciii.es

Vicenta González Mora (VG), National Centre of Tropical Medicine-Institute of Health Carlos III. vgonzalez@isciii.es

Luz García García (LG), National Centre of Tropical Medicine-Institute of Health Carlos III. luzgarcia@isciii.es

Ana Rodriguez-Galet (ARG), National Centre of Tropical Medicine-Institute of Health Carlos III and HIV molecular epidemiology laboratory. Ramón y Cajal-IRyCIS Hospital. argalet@salud.madrid.org

Ramón Diaz-Regañon (RDR), National Centre of Tropical Medicine-Institute of Health Carlos III. r.diaz@isciii.es

Rosario Galán (RG), National Centre of Tropical Medicine-Institute of Health Carlos III. chgalanelez@isciii.es

Laura Cerrada-Gálvez (LCG), National Centre of Tropical Medicine-Institute of Health Carlos III. lacerrad@ucm.es

Policarpo Ncogo (PN), State Foundation, Health, Childhood and Social Welfare FSP. pncogo@psglobal.es

Matilde Riloha (MR), Ministry of Health and Social Welfare-Malaria National Programme of Equatorial Guinea. riloharivas@yahoo.es

Page $13 / 20$ 
Agustín Benito Llanes (AB), National Centre of Tropical Medicine-Institute of Health Carlos III. abenito@isciii.es

\section{References}

1. World Malaria Report. 2020 [Internet]. [cited 2021 Jun 15]. Available from: https://www.who.int/teams/global-malariaprogramme/reports/world-malaria-report-2020.

2. White NJ. Antimalarial drug resistance. J Clin Invest. 2004;113:1084-92.

3. World Health Organitation. Global Report on antimarial drug efficacy and drug resistance: 2000-2010. WHO library Cataloguing-Publication Data; 2010.

4. Charle P, Berzosa P, Descalzo MA, de Lucio A, Raso J, Obono J, et al. Efficacy of Artesunate + Sulphadoxine-Pyrimethamine (AS + SP) and Amodiaquine + Sulphadoxine-Pyrimethamine (AQ + SP) for Uncomplicated falciparum Malaria in Equatorial Guinea (Central Africa). J Trop Med. 2009;2009:781865.

5. Charle P, Berzosa P, de Lucio A, Raso J, Nseng Nchama G, Benito A. Artesunate/amodiaquine malaria treatment for Equatorial Guinea (Central Africa). Am J Trop Med Hyg. 2013;88:1087-92.

6. Rivas MR, Warsame M. Ramona Mbá Andeme, Salomón Nsue Esidang, Policarpo Ricardo Ncogo, Wonder Philip Phiri, et al. Therapeutic efficacy of artesunate-amodiaquine and artemether-lumefantrine and polymorphism in Plasmodium falciparum kelch13-propeller gene in Equatorial Guinea. Malaria Journal. 20:275.

7. National Malaria Therapeutic Guidelines-Equatorial Guinea. World Health Organization/ Institute of Health Carlos III/National Malaria Programme. Ministry of Health and Social Welfare of equatorial Guinea; 2020.

8. Korenromp EL, Williams BG, Gouws E, Dye C, Snow RW. Measurement of trends in childhood malaria mortality in Africa: an assessment of progress toward targets based on verbal autopsy. Lancet Infect Dis. 2003;3:349-58.

9. Kavishe RA, Paulo P, Kaaya RD, Kalinga A, van Zwetselaar M, Chilongola J, et al. Surveillance of artemether-lumefantrine associated Plasmodium falciparum multidrug resistance protein-1 gene polymorphisms in Tanzania. Malar J. 2014;13:264.

10. Thu AM, Phyo AP, Landier J, Parker DM, Nosten FH. Combating multidrug-resistant Plasmodium falciparum malaria. FEBS J. 2017;284:2569-78.

11. Oboh MA, Singh US, Antony HA, Ndiaye D, Badiane AS, Ali NA, et al. Molecular epidemiology and evolution of drug-resistant genes in the malaria parasite Plasmodium falciparum in southwestern Nigeria. Infect Genet Evol. 2018;66:222-8.

12. Henry M, Florey L, Youll S, Gutman JR. An analysis of country adoption and implementation of the 2012 WHO recommendations for intermittent preventive treatment for pregnant women in sub-Saharan Africa. Malar J. 2018;17:364.

13. Organization WH. WHO policy recommendation on intermittent preventive treatment during infancy with sulphadoxine-pyrimethamine (SPIPTi) for plasmodium falciparum malaria control in Africa. World Health Organization; 2010 [cited 2021 Jun 16]; Available from: https://apps.who.int/iris/handle/10665/337977.

14. Amenga-Etego LN, Asoala V, Agongo G, Jacob C, Goncalves S, Awandare GA, et al. Temporal evolution of sulfadoxine-pyrimethamine resistance genotypes and genetic diversity in response to a decade of increased interventions against Plasmodium falciparum in northern Ghana. Malar J. 2021;20:152.

15. Nkoli Mandoko P, Rouvier F, Matendo Kakina L, Moke Mbongi D, Latour C, Losimba Likwela J, et al. Prevalence of Plasmodium falciparum parasites resistant to sulfadoxine/pyrimethamine in the Democratic Republic of the Congo: emergence of highly resistant pfdhfr/pfdhps alleles. J Antimicrob Chemother. 2018;73:2704-15.

16. Cisse M, Awandare GA, Soulama A, Tinto H, Hayette M-P, Guiguemdé RT. Recent uptake of intermittent preventive treatment during pregnancy with sulfadoxine-pyrimethamine is associated with increased prevalence of Pfdhfr mutations in Bobo-Dioulasso, Burkina Faso. Malar J. 2017;16:38.

17. Esu E, Tacoli C, Gai P, Berens-Riha N, Pritsch M, Loescher T, et al. Prevalence of the Pfdhfr and Pfdhps mutations among asymptomatic pregnant women in Southeast Nigeria. Parasitol Res. 2018;117:801-7.

18. Naidoo I, Roper C. Mapping "partially resistant", "fully resistant", and "super resistant" malaria. Trends Parasitol. 2013;29:505-15.

19. Ndam NT, Basco LK, Ngane VF, Ayouba A, Ngolle EM, Deloron P, et al. Reemergence of chloroquine-sensitive pfcrt K76 Plasmodium falciparum genotype in southeastern Cameroon. Malar J. 2017;16:130.

20. Moyeh MN, Njimoh DL, Evehe MS, Ali IM, Nji AM, Nkafu DN, et al. Effects of Drug Policy Changes on Evolution of Molecular Markers of Plasmodium falciparum Resistance to Chloroquine, Amodiaquine, and Sulphadoxine-Pyrimethamine in the South West Region of Cameroon. Malar Res Treat. 2018;2018:7071383.

21. Omar S, Makokha, Fathia, Kimani M. Prevalence of Plasmodium falciparum chloroquine resistant gene markers, Pfcrt-76 and pfmdr1-86, eight years after ceesation of chloroquine use in Mwea, Kenya. The $\mathrm{J}$ of infect in developing countries. 2007;1:195-201. 
22. Kublin JG, Cortese JF, Njunju EM, Mukadam RAG, Wirima JJ, Kazembe PN, et al. Reemergence of chloroquine-sensitive Plasmodium falciparum malaria after cessation of chloroquine use in Malawi. J Infect Dis. 2003;187:1870-5.

23. Laufer MK, Thesing PC, Eddington ND, Masonga R, Dzinjalamala FK, Takala SL, et al. Return of chloroquine antimalarial efficacy in Malawi. N Engl J Med. 2006;355:1959-66.

24. Happi CT, Gbotosho GO, Folarin OA, Bolaji OM, Sowunmi A, Kyle DE, et al. Association between mutations in Plasmodium falciparum chloroquine resistance transporter and $\mathrm{P}$. falciparum multidrug resistance 1 genes and in vivo amodiaquine resistance in P. falciparum malaria-infected children in Nigeria. Am J Trop Med Hyg. 2006;75:155-61.

25. Ikegbunam MN, Nkonganyi CN, Thomas BN, Esimone CO, Velavan TP, Ojurongbe O. Analysis of Plasmodium falciparum Pfcrt and Pfmdr1 genes in parasite isolates from asymptomatic individuals in Southeast Nigeria 11 years after withdrawal of chloroquine. Malar J. 2019;18:343.

26. Ocan M, Akena D, Nsobya S, Kamya MR, Senono R, Kinengyere AA, et al. K13-propeller gene polymorphisms in Plasmodium falciparum parasite population in malaria affected countries: a systematic review of prevalence and risk factors. Malar J. 2019;18:60.

27. Pacific WHORO, for the. W. Strategy for malaria elimination in the Greater Mekong Subregion: 2015-2030 [Internet]. Manila : WHO Regional Office for the Western Pacific; 2015 [cited 2021 Jun 16]. Available from: https://apps.who.int/iris/handle/10665/208203.

28. WHO-CDS-GMP-2018.18-eng.pdf [Internet]. [cited 2021 Jun 16]. Available from: https://apps.who.int/iris/bitstream/handle/10665/274362/WHO-CDS-GMP-2018.18-eng.pdf?ua=1.

29. Ariey F, Witkowski B, Amaratunga C, Beghain J, Langlois A-C, Khim N, et al. A molecular marker of artemisinin-resistant Plasmodium falciparum malaria. Nature. 2014;505:50-5.

30. Cheeseman IH, Miller BA, Nair S, Nkhoma S, Tan A, Tan JC, et al. A major genome region underlying artemisinin resistance in malaria. Science. 2012;336:79-82.

31. Ashley EA, Dhorda M, Fairhurst RM, Amaratunga C, Lim P, Suon S, et al. Spread of artemisinin resistance in Plasmodium falciparum malaria. N Engl J Med. 2014;371:411-23.

32. Ménard D, Khim N, Beghain J, Adegnika AA, Shafiul-Alam M, Amodu O, et al. A Worldwide Map of Plasmodium falciparum K13-Propeller Polymorphisms. N Engl J Med. 2016;374:2453-64.

33. MalariaGEN Plasmodium falciparum Community Project. Genomic epidemiology of artemisinin resistant malaria. Neher RA, editor. eLife. eLife Sciences Publications, Ltd; 2016;5:p. e08714.

34. Kamau E, Campino S, Amenga-Etego L, Drury E, Ishengoma D, Johnson K, et al. K13-propeller polymorphisms in Plasmodium falciparum parasites from sub-Saharan Africa. J Infect Dis. 2015;211:1352-5.

35. Conrad MD, Bigira V, Kapisi J, Muhindo M, Kamya MR, Havlir DV, et al. Polymorphisms in K13 and falcipain-2 associated with artemisinin resistance are not prevalent in Plasmodium falciparum isolated from Ugandan children. PLoS One. 2014;9:e105690.

36. Ishengoma DS, Mandara Cl, Francis F, Talundzic E, Lucchi NW, Ngasala B, et al. Efficacy and safety of artemether-lumefantrine for the treatment of uncomplicated malaria and prevalence of Pfk13 and Pfmdr1 polymorphisms after a decade of using artemisinin-based combination therapy in mainland Tanzania. Malar J. 2019;18:88.

37. Eboumbou Moukoko CE, Huang F, Nsango SE, Kojom Foko LP, Ebong SB, Epee Eboumbou P, et al. K-13 propeller gene polymorphisms isolated between 2014 and 2017 from Cameroonian Plasmodium falciparum malaria patients. PLoS One. 2019;14:e0221895.

38. Ta TH, Hisam S, Lanza M, Jiram Al, Ismail N, Rubio JM. First case of a naturally acquired human infection with Plasmodium cynomolgi. Malar J. 2014;13:68.

39. Rubio JM, Post RJ, van Leeuwen WMD, Henry MC, Lindergard G, Hommel M. Alternative polymerase chain reaction method to identify Plasmodium species in human blood samples: the semi-nested multiplex malaria PCR (SnM-PCR). Trans R Soc Trop Med Hyg. 2002;96(Suppl 1):199-204.

40. Plowe CV, Djimde A, Bouare M, Doumbo O, Wellems TE. Pyrimethamine and proguanil resistance-conferring mutations in Plasmodium falciparum dihydrofolate reductase: polymerase chain reaction methods for surveillance in Africa. Am J Trop Med Hyg. 1995;52:565-8.

41. Protocols | University of Maryland School of Medicine [Internet]. [cited 2021 Jun 16]. Available from: https://www.medschool.umaryland.edu/malaria/protocols/.

42. Didier M, Menard D, Ariey F. PCR_Sequencing for genotyping SNPs PF3D7_1343700 Kelch protein propeller domain. Protocol Exchange [Internet]. 2013 [cited 2021 Jun 16]; Available from: http://www.nature.com/protocolexchange/protocols/2927.

43. Altschul SF, Gish W, Miller W, Myers EW, Lipman DJ. Basic local alignment search tool. J Mol Biol. 1990;215:403-10.

44. Benito A, Roche J, Molina R, Amela C, Alvar J. In vitro susceptibility of Plasmodium falciparum to chloroquine, amodiaquine, quinine, mefloquine, and sulfadoxine/pyrimethamine in Equatorial Guinea. Am J Trop Med Hyg. 1995;53:526-31.

45. Roche J, Guerra-Neira A, Raso J, Benito A. Surveillance of in vivo resistance of Plasmodium falciparum to antimalarial drugs from 1992 to 1999 in Malabo (Equatorial Guinea). Am J Trop Med Hyg. 2003;68:598-601. 
46. Fidock DA, Nomura T, Talley AK, Cooper RA, Dzekunov SM, Ferdig MT, et al. Mutations in the P. falciparum digestive vacuole transmembrane protein PfCRT and evidence for their role in chloroquine resistance. Mol Cell. 2000;6:861-71.

47. Achieng AO, Muiruri P, Ingasia LA, Opot BH, Juma DW, Yeda R, et al. Temporal trends in prevalence of Plasmodium falciparum molecular markers selected for by artemether-lumefantrine treatment in pre-ACT and post-ACT parasites in western Kenya. Int $\mathrm{J}$ Parasitol Drugs Drug Resist. 2015;5:92-9.

48. Ocan M, Akena D, Nsobya S, Kamya MR, Senono R, Kinengyere AA, et al. Persistence of chloroquine resistance alleles in malaria endemic countries: a systematic review of burden and risk factors. Malar J. 2019;18:76.

49. Windle ST, Lane KD, Gadalla NB, Liu A, Mu J, Caleon RL, et al. Evidence for linkage of pfmdr1, pfcrt, and pfk13 polymorphisms to lumefantrine and mefloquine susceptibilities in a Plasmodium falciparum cross. Int J Parasitol Drugs Drug Resist. 2020;14:208-17.

50. Sisowath C, Strömberg J, Mårtensson A, Msellem M, Obondo C, Björkman A, et al. In vivo selection of Plasmodium falciparum pfmdr1 86N coding alleles by artemether-lumefantrine (Coartem). J Infect Dis. 2005;191:1014-7.

51. Eyase FL, Akala HM, Ingasia L, Cheruiyot A, Omondi A, Okudo C, et al. The role of Pfmdr1 and Pfcrt in changing chloroquine, amodiaquine, mefloquine and lumefantrine susceptibility in western-Kenya P. falciparum samples during 2008-2011. PLoS One. 2013;8:e64299.

52. Conrad MD, LeClair N, Arinaitwe E, Wanzira H, Kakuru A, Bigira V, et al. Comparative impacts over 5 years of artemisinin-based combination therapies on Plasmodium falciparum polymorphisms that modulate drug sensitivity in Ugandan children. J Infect Dis. 2014;210:344-53.

53. Venkatesan M, Gadalla NB, Stepniewska K, Dahal P, Nsanzabana C, Moriera C, et al. Polymorphisms in Plasmodium falciparum chloroquine resistance transporter and multidrug resistance 1 genes: parasite risk factors that affect treatment outcomes for $P$. falciparum malaria after artemether-lumefantrine and artesunate-amodiaquine. Am J Trop Med Hyg. 2014;91:833-43.

54. Baraka V, Tinto H, Valea I, Fitzhenry R, Delgado-Ratto C, Mbonye MK, et al. In vivo selection of Plasmodium falciparum Pfcrt and Pfmdr1 variants by artemether-lumefantrine and dihydroartemisinin-piperaquine in Burkina Faso. Antimicrob Agents Chemother. 2015;59:734-7.

55. Bacon DJ, Tang D, Salas C, Roncal N, Lucas C, Gerena L, et al. Effects of point mutations in Plasmodium falciparum dihydrofolate reductase and dihydropterate synthase genes on clinical outcomes and in vitro susceptibility to sulfadoxine and pyrimethamine. PLoS One. 2009;4:e6762.

56. Berzosa P, Esteban-Cantos A, García L, González V, Navarro M, Fernández T, et al. Profile of molecular mutations in pfdhfr, pfdhps, pfmdr1, and pfcrt genes of Plasmodium falciparum related to resistance to different anti-malarial drugs in the Bata District (Equatorial Guinea). Malar J. 2017;16:28.

57. Lin L-Y, Li J, Huang H-Y, Liang X-Y, Jiang T-T, Chen J-T, et al. Trends in Molecular Markers Associated with Resistance to SulfadoxinePyrimethamine (SP) Among Plasmodium falciparum Isolates on Bioko Island, Equatorial Guinea: 2011-2017. Infect Drug Resist. 2020;13:1203-12.

58. Romay-Barja M, Ncogo P, Nseng G, Santana-Morales MA, Berzosa P, Herrador Z, et al. The use and preference of artemether as a first-choice treatment for malaria: results from a cross-sectional survey in the Bata district, Equatorial Guinea. Malar J. 2018;17:107.

59. Ruh E, Bateko JP, Imir T, Taylan-Ozkan A. Molecular identification of sulfadoxine-pyrimethamine resistance in malaria infected women who received intermittent preventive treatment in the Democratic Republic of Congo. Malar J. 2018;17:17.

60. Voumbo-Matoumona DF, Kouna LC, Madamet M, Maghendji-Nzondo S, Pradines B, Lekana-Douki JB. Prevalence of Plasmodium falciparum antimalarial drug resistance genes in Southeastern Gabon from 2011 to 2014. Infect Drug Resist. 2018;11:1329-38.

61. Chauvin P, Menard S, Iriart X, Nsango SE, Tchioffo MT, Abate L, et al. Prevalence of Plasmodium falciparum parasites resistant to sulfadoxine/pyrimethamine in pregnant women in Yaoundé, Cameroon: emergence of highly resistant pfdhfr/pfdhps alleles. J Antimicrob Chemother. 2015;70:2566-71.

62. Ministry of Health and Social Welfare of Equatorial Guinea, National Malaria Programme, Equatorial Guinea, National Centre of Tropical Medicine, Institute of Health Carlos III (Spain). Evaluation of the efficacy of artesunate + amodiaquine in uncomplicated Plasmodium falciparum malaria. (2010). 2011.

63. Banek K, Webb EL, Smith SJ, Chandramohan D, Staedke SG. Adherence to treatment with artemether-lumefantrine or amodiaquineartesunate for uncomplicated malaria in children in Sierra Leone: a randomized trial. Malar J. 2018;17:222.

64. Mita T, Tanabe K. Evolution of Plasmodium falciparum drug resistance: implications for the development and containment of artemisinin resistance. Jpn J Infect Dis. 2012;65:465-75.

65. Torrentino-Madamet M, Fall B, Benoit N, Camara C, Amalvict R, Fall M, et al. Limited polymorphisms in k13 gene in Plasmodium falciparum isolates from Dakar, Senegal in 2012-2013. Malar J. 2014;13:472.

66. Djaman JA, Olefongo D, Ako AB, Roman J, Ngane VF, Basco LK, et al. Molecular Epidemiology of Malaria in Cameroon and Côte d'Ivoire. XXXI. Kelch 13 Propeller Sequences in Plasmodium falciparum Isolates before and after Implementation of Artemisinin-Based Combination Therapy. Am J Trop Med Hyg. 2017;97:222-4. 
67. de Laurent ZR, Chebon LJ, Ingasia LA, Akala HM, Andagalu B, Ochola-Oyier LI, et al. Polymorphisms in the K13 Gene in Plasmodium falciparum from Different Malaria Transmission Areas of Kenya. Am J Trop Med Hyg. 2018;98:1360-6.

68. Safeukui I, Fru-Cho J, Mbengue A, Suresh N, Njimoh DL, Bumah VV, et al. Investigation of polymorphisms in the P. falciparum artemisinin resistance marker kelch13 in asymptomatic infections in a rural area of Cameroon. bioRxiv. Cold Spring Harbor Laboratory; 2017.

p. 148999.

69. Li J, Chen J, Xie D, Eyi UM, Matesa RA, Ondo Obono MM, et al. Limited artemisinin resistance-associated polymorphisms in Plasmodium falciparum K13-propeller and PfATPase6 gene isolated from Bioko Island, Equatorial Guinea. Int J Parasitol Drugs Drug Resist. 2016;6:549.

\section{Figures}

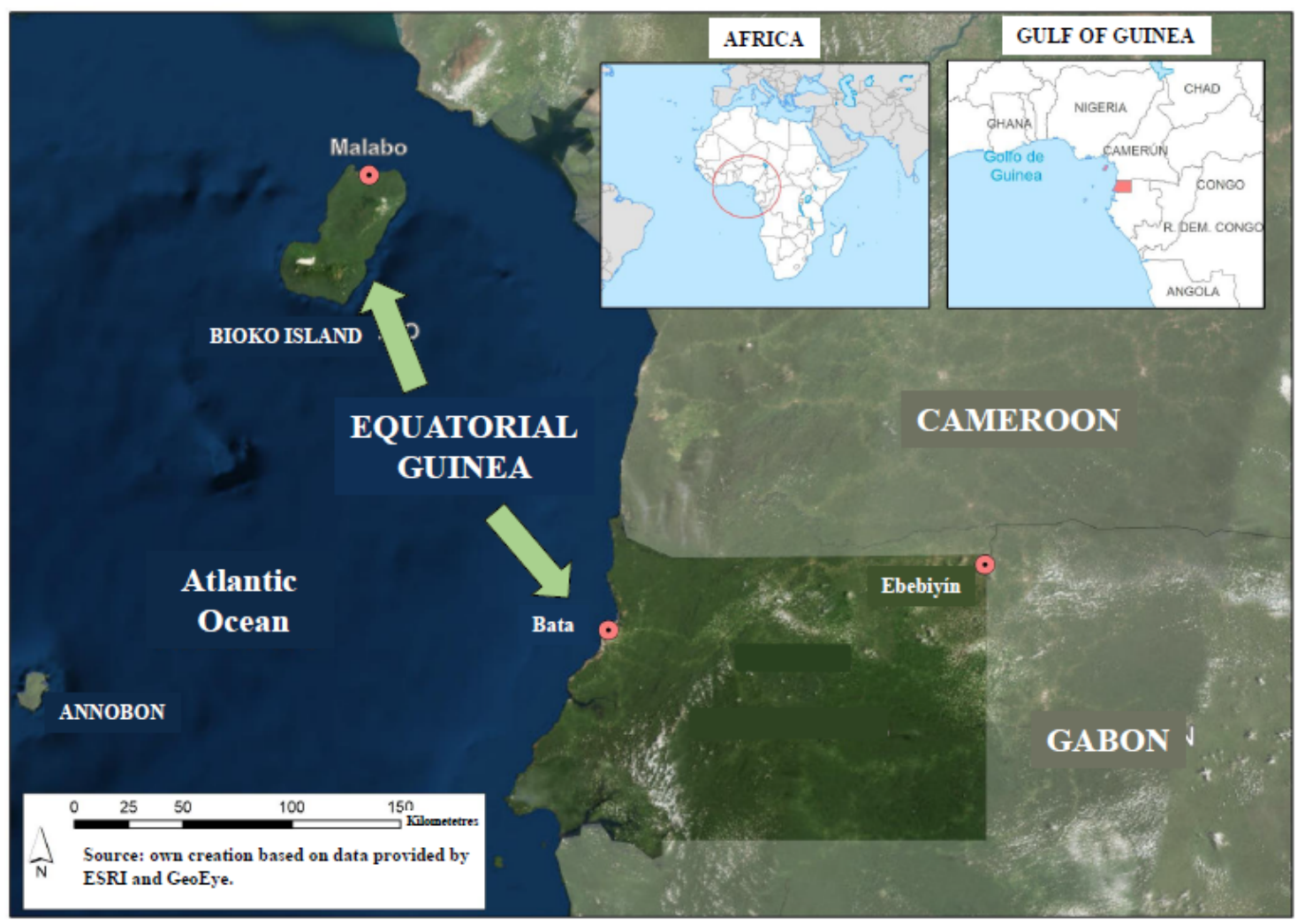

\section{Figure 1}

Map of the location of Equatorial Guinea in Africa The small boxes show the location of Equatorial Guinea on the African continent. Then the two regions of the country are indicated, the Island Region: Bioko Island where is the capital city and Annobon, and the Continental Region between Cameroon and Gabon. 


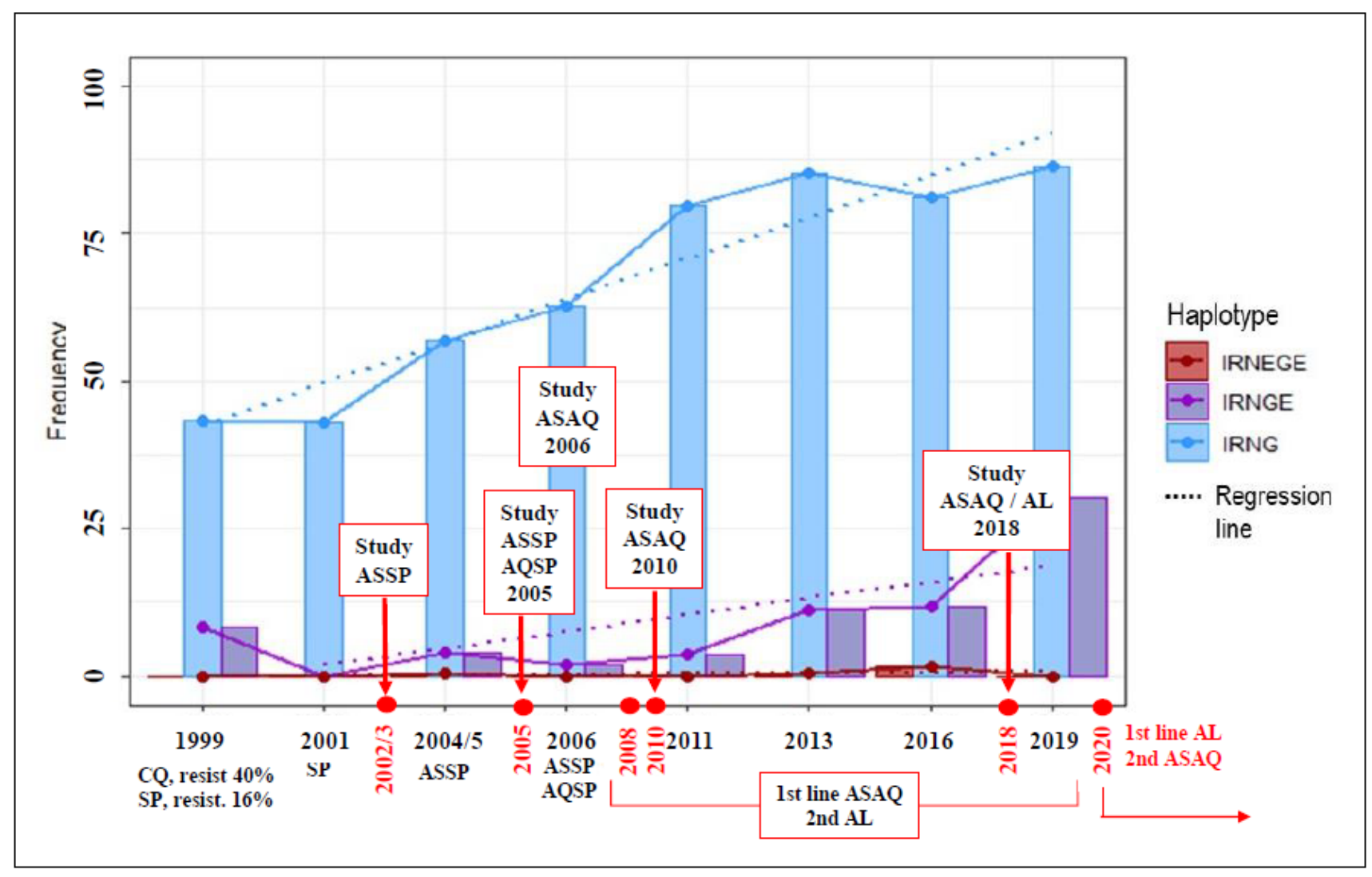

Figure 2

Evolution of haplotype frequencies over time I The upward trend of the partially (51I/59R/108N/437G, IRNG) and fully resistant (51I/59R/108N/437G/540E, IRNGE) haplotypes is shown over time, except for the super-resistant haplotype (51I/59R/108N/437G/540E/581G, IRNEGE) which is observed with a downward trend. The regression line (dotted line) indicates the upward and downward trends of each haplotype. The figure highlights the different efficacy studies that have been carried out in Equatorial Guinea, as well as the changes in treatments until 2020.

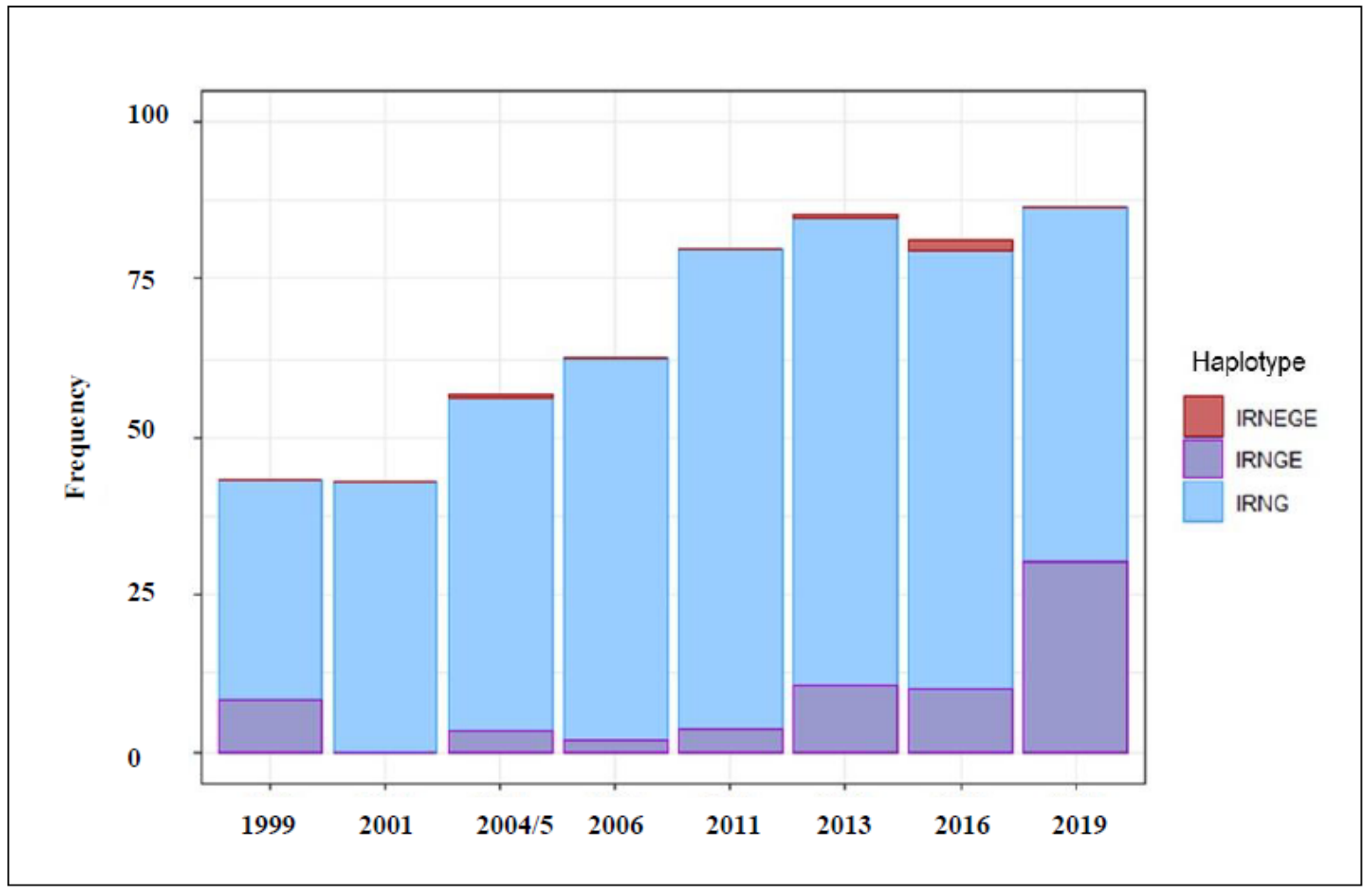




\section{Figure 3}

Evolution of haplotype frequencies over time II The frequency of each haplotype is shown in the figure taking each parasite only once with the maximum number of mutations. Over all years the most frequent is partially resistant (IRNG), secondly fully resistant (IRNGE). Super resistant (IRNEGE) is always at a very low frequency or absent. In 2019 can be seen that already the fully resistant has increased at the expense of decreasing the relative frequency of the partially resistant (IRNG). Haplotypes: Partially resistant IRNG, Fully IRNGE and Super Resistant IRNEGE.

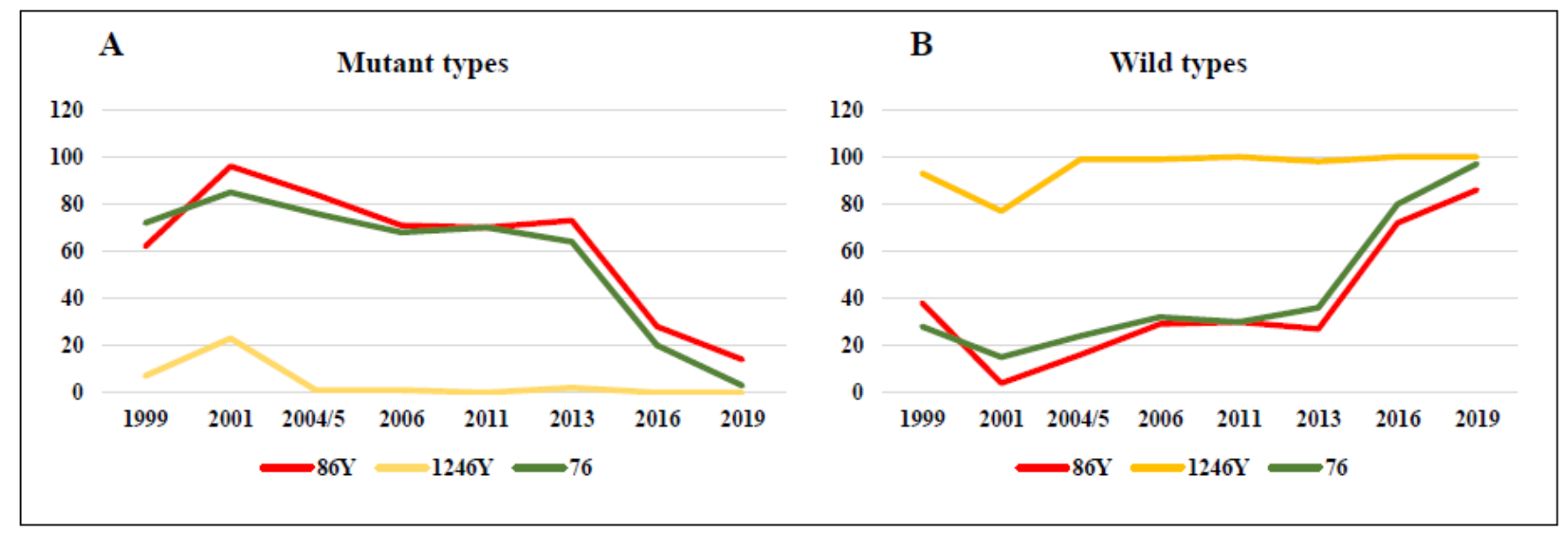

Figure 4

Evolution of mutant and wild types over time Graphic A shows how mutant populations are decreasing over time, while graphic B shows how wild populations are increasing. Since the withdrawal of chloroquine (CQ) as a treatment, the selective pressure exerted by $\mathrm{CQ}$ is removed, so wild populations tend to increase over time.

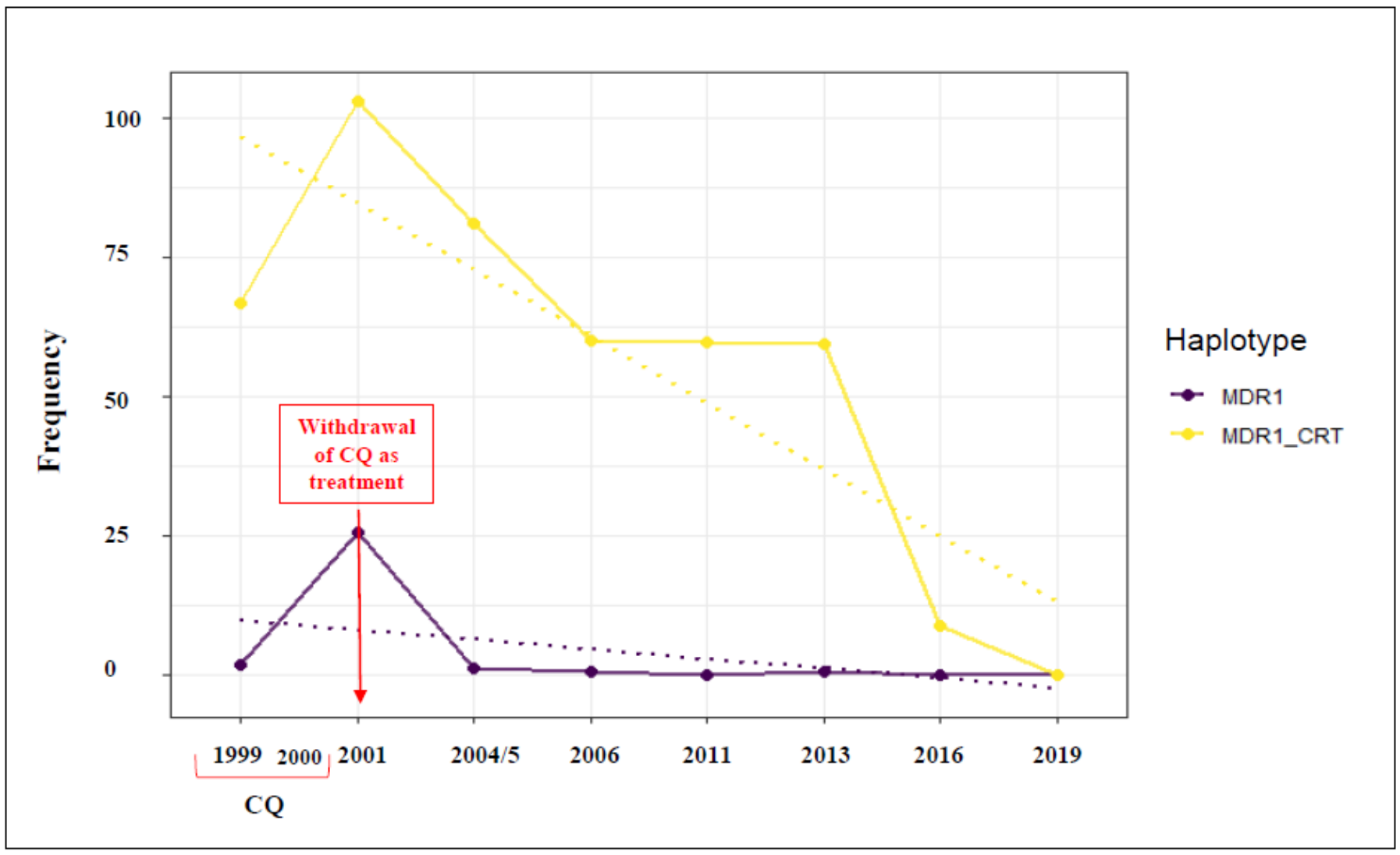

Figure 5

Evolution of pfmdr1 and pfmdr1+pfcrt haplotypes over time It is showed the evolution of the frequency of haplotypes in pfmdr1 and pfcrt, since the withdrawal of CQ as a treatment in Equatorial Guinea. The downward trends of haplotypes 86Y/1246Y (MDR1) and 86Y/76T (MDR1_CRT) were represented by the regression line (dotted line) indicating a sharp decrease. 


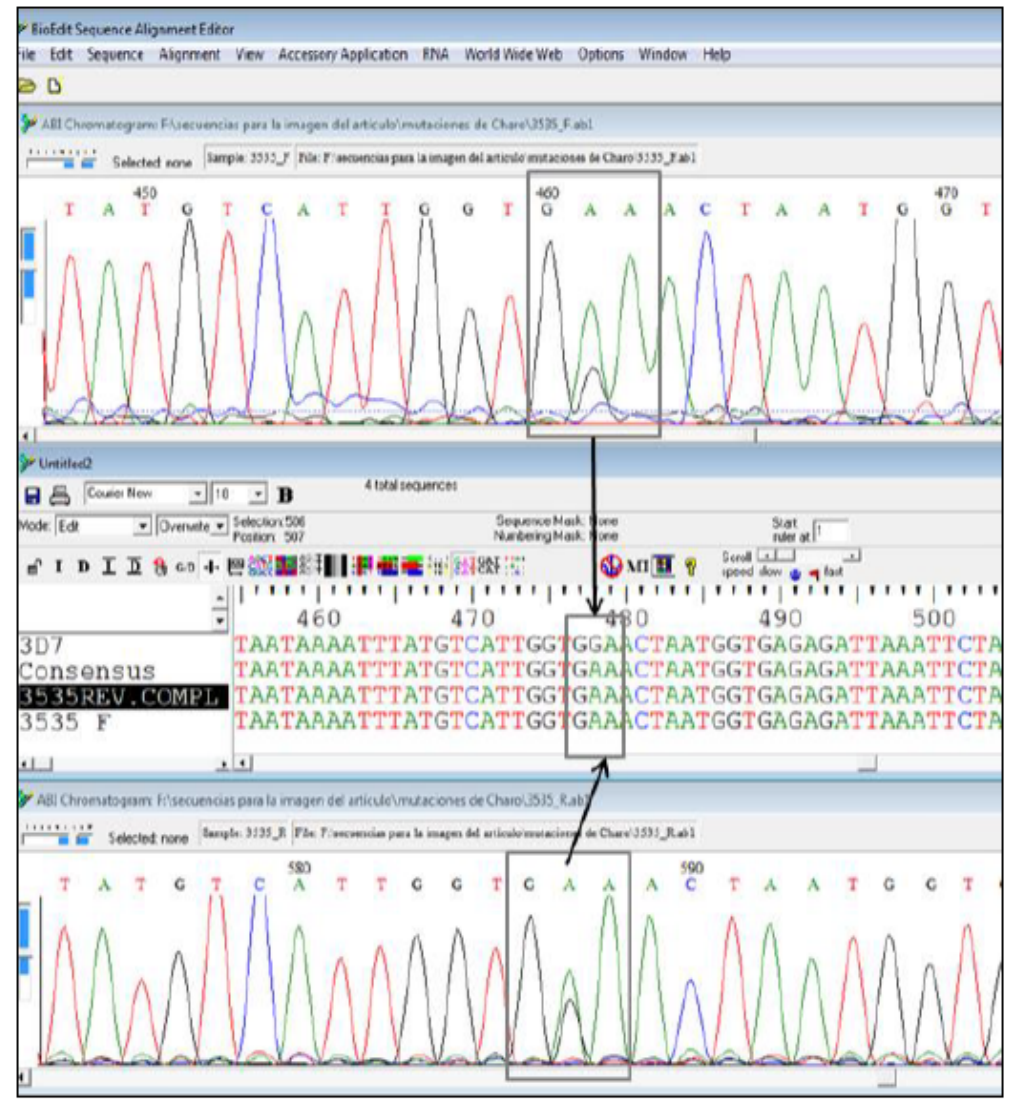

\section{Figure 6}

Comparison of forward and reverse sequences It is showed the alignment and electropherograms of the forward and reverse complement sequences compared to the 3D7 sequence. The area where the mutation is detected is boxed. A peak corresponding to an $\mathrm{A}$ (mutant) is observed in both cases and below it, almost with the same intensity, a smaller peak corresponding to a $G$ (wild). Therefore, could be a mix of $P$. falciparum GAA (mutant population) and with GGA (wild type population) could be inferred. 